\title{
Research on Sulfate Attack Mechanism of Cement Concrete Based on Chemical Thermodynamics
}

\author{
Peng Liu $\mathbb{D}^{1,2}$ Ying Chen $\mathbb{D}^{1,},{ }^{1,2,3}$ Zhiwu Yu, ${ }^{1,2}$ Lingkun Chen, ${ }^{4}$ and Yongfeng Zheng $\mathbb{D}^{5}$ \\ ${ }^{1}$ School of Civil Engineering, Central South University, 22 Shaoshan Road, Changsha 410075, China \\ ${ }^{2}$ National Engineering Laboratory for High Speed Railway Construction, 22 Shaoshan Road, Changsha 410075, China \\ ${ }^{3}$ School of Civil Engineering, Central South University of Forestry and Technology, 498 Shaoshan Road, Changsha 410004, China \\ ${ }^{4}$ School of Civil Engineering, Southwest Jiaotong University, 6 Jingqu Road, Chengdu 610031, China \\ ${ }^{5}$ Key Laboratory of Building Structural Retrofitting and Underground Space Engineering, Shandong Jianzhu University, \\ Ministry of Education, Jinan, Shandong 250101, China
}

Correspondence should be addressed to Ying Chen; cheny83@csu.edu.cn and Yongfeng Zheng; zhyf-fb@163.com

Received 18 September 2019; Revised 16 December 2019; Accepted 28 January 2020; Published 9 March 2020

Academic Editor: Mohammad A. Hariri-Ardebili

Copyright $(2020$ Peng Liu et al. This is an open access article distributed under the Creative Commons Attribution License, which permits unrestricted use, distribution, and reproduction in any medium, provided the original work is properly cited.

Based on principles of chemical thermodynamics, the relationship between temperature and the Gibbs free energy of erosion products generated during the sulfate attack on cement concrete was deduced. The orientation of chemical reactions of sulfate attack on cement concrete was theoretically determined as well as the critical sulfate ion concentration and the formation conditions of erosion products. The phase composition, microstructure, crystal form, and morphology of erosion products before and after sulfate attack were investigated by environmental scanning electron microscope and energy spectrum analysis (ESEM-EDS) and X-ray diffraction (XRD). The results show that the effects of sulfate ion concentration and temperature on cement concrete sulfate attack are significant, and different influencing factors correlate with each other. The crystal transition temperature between the anhydrite and dihydrate gypsum is $42^{\circ} \mathrm{C}$, and the corresponding concentration of sulfate ion is about $2.3 \times 10^{-3} \mathrm{~mol} / \mathrm{L}$. Simultaneously, the crystal transition temperature between the thenardite and mirabilite is $32.4^{\circ} \mathrm{C}$. Moreover, the theoretical upper limit temperature and sulfate ion lower limit concentration of thaumasite are $44^{\circ} \mathrm{C}$ and $0.0023 \mathrm{~mol} / \mathrm{L}$, respectively. The ESEM-EDS and XRD results imply that the chemical thermodynamics can be used to reveal the erosion mechanism of sulfate attack on cement concrete. The major erosion products of sulfate attack on cement concrete are rod-like ettringite with a larger slenderness ratio, plate-like gypsum, granular sulfate salt, incompletely corroded calcium hydroxide, and residual skeleton of calcium silicate hydrate. The sulfate attack has double effects on mechanical properties of specimens, which can affect the microstructure, phase composition, type, and morphology of erosion products.

\section{Introduction}

Sulfate attack on cement concrete can degrade the durability and reduce the service life of concrete building structures $[1,2]$. There are plenty of influence factors of sulfate attack on concrete, which are mainly focused on the kind and concentration of sulfate solution, temperature, $\mathrm{pH}$ value, cement composition, admixtures, and erosion form [3-7]. Among them, the temperature, concentration, and type of the sulfate solution are considered as the most important factors of sulfate attack $[1,8,9]$. For example, Valencia et al.
[10] indicated that the $\mathrm{MgSO}_{4}$ had more influence on the deterioration of concrete than that of $\mathrm{Na}_{2} \mathrm{SO}_{4}$; the results showed that after attacked for 360 days in $5 \% \mathrm{MgSO}_{4}$ solution, the concrete expanded by $0.04 \%$, and its mechanical resistance decreased by $33 \%$. Axel et al. [11] regarded the erosion product as monosulfate when the concentration of sulfate ion was less than $1 \mathrm{~g} / \mathrm{L}$. Lawrence [12] proposed that the highest stable temperature of the ettringite (AFt) was about $65^{\circ} \mathrm{C} \sim 70^{\circ} \mathrm{C}$, and the AFt was decomposed when the temperature was higher than $70^{\circ} \mathrm{C}$ [13]. Hekal et al. [14] investigated the variation of the strength of the concrete 
under different circumstances, and they declared that the high temperature of $60^{\circ} \mathrm{C}$ played a significant effect on mechanical properties of concrete. Dehwah [15] investigated the effect of sodium sulfate concentrations (to yield $1 \%$, $2.5 \%$, and $4 \%\left[\mathrm{SO}_{4}{ }^{2-}\right]$ ) on concrete deterioration and morphological changes in cement hydrates; their results indicated that the deterioration was noted in the plain and fly ash cement concrete specimens exposed to sodium chloride admixed with magnesium sulfate. In general, the sulfate solution concentration and temperature have remarkable influence on sulfate erosion mechanism, crystal form and type, erosion rate, spontaneity of reaction, and stable existence condition [16]. Therefore, it is very important to investigate the effects of sulfate solution concentration and temperature on sulfate attack of concrete.

Although a lot of achievements of sulfate attack on cement concrete have been made [17], some divergences of sulfate solution concentration and temperature on sulfate attack also exist. For example, Biczok [18] considered that the erosion products of sulfate attack on concrete were AFt and gypsum when $\left[\mathrm{SO}_{4}{ }^{2-}\right]$ was less than $1 \mathrm{~g} / \mathrm{L}$ and more than $8 \mathrm{~g} / \mathrm{L}$, respectively, and gypsum and AFt could be observed when $\left[\mathrm{SO}_{4}{ }^{2-}\right]$ ranged from $1 \mathrm{~g} / \mathrm{L}$ to $8 \mathrm{~g} / \mathrm{L}$. Bellmann et al. [19] pointed out that the portlandite reacted to gypsum at a minimal sulfate concentration of approximately $1400 \mathrm{mg} / \mathrm{L}$ $(\mathrm{pH}=12.45)$. Zhang et al. [20] conducted the accelerated laboratory tests on resistance of concrete exposed to sulfate attack with high concentration sulfate solutions or under drastic drying-wetting cycle conditions; their results showed that the exposure regime of full immersion in $2.1 \%$ sulfate sodium solutions subjected to natural drying-wetting cycles can well reproduce the field exposure condition of concrete under certain sulfate-rich environments. Both concentration and exposure type affect the nature of sulfate attack mechanism on concrete, along with the evolution of physical and mechanical properties. Yu et al. [21] investigated the evolution properties of the cement mortar fully immersed in sodium sulfate solutions of different concentrations $(0 \%, 5 \%$, and $15 \%$ ); their results showed that the properties deterioration at the late stage was accelerated with increase of the concentration of the sodium sulfate solution. Santhanam [22] carried out an experimental investigation to understand the influence of the solution concentration of seawater on performance of the cement mortars, and the results indicated that higher concentrations of seawater did not cause the same level of damage as higher concentrations of groundwater relative to the typical seawater/groundwater solutions. The temperature not only affects the reaction rate and diffusion of ions, but also changes the erosion mechanism and products in cement concrete. Xie et al. [23] proposed a novel theory concerning sulfate expansion phenomena in cement concrete systems based on the principles of chemical thermodynamics, and their results showed that temperature had a significant effect on the concrete expansion. Blanco-Varela et al. [24] regarded that the low temperature of less than $15^{\circ} \mathrm{C}$ as one of the essential conditions for the formation of thaumasite (CSCSH). Hartshorn et al. [25] demonstrated that plenty of thaumasite could be generated at $5^{\circ} \mathrm{C}$, and a little of thaumasite could also be formed at $20^{\circ} \mathrm{C}$, which caused a deterioration of concrete. However, Santhanam [5] proposed that the forming condition of thaumasite was temperature less than $20^{\circ} \mathrm{C}$, and the carbonation was another essential condition. Moreover, Brown et al. [26] employed the scanning electron microscope (SEM) to investigate the thaumasite generated in concrete attacked by sulfate, and their results indicated that the formation of thaumasite was related to concrete carbonation.

Although many achievements regarding the effects of sulfate solution concentration and temperature on the erosion mechanism of sulfate attack have been made, the researches of sulfate attack on cement concrete based on principles of chemical thermodynamics have no breakthrough progress as yet. Furthermore, there exists a deviation between the theoretical analysis and the in-site test results. The objective of this study is to investigate the relationship between temperature and the Gibbs free energy of the erosion products generated during the sulfate attack based on the principle of chemical thermodynamics. The orientation of chemical reactions of sulfate attack on concrete was theoretically determined as well as the critical sulfate ion concentration and forming conditions of erosion products. Moreover, the phase composition, microstructure, crystal form, and morphology of erosion products of cement before and after sulfate attack were studied by ESEM-EDS and XRD. The research results in this study can provide a support for the erosion mechanism of sulfate attack, crystal form, and forming conditions of erosion products in cement concrete.

\section{Theoretical Analysis}

The sulfate attack on cement concrete is a complex physical and chemical process $[4,5]$. The temperature and sulfate solution concentration have remarkable effects on the thermodynamic equilibrium state of the reaction, so it is very important to establish their international relationship. In order to simplify the theoretical analysis, we assume that the temperature and concentration of various ions are uniform and unchangeable, and the theoretical analysis of thermodynamic equilibrium state of the sulfate attack on cement concrete is conducted as in the following section.

2.1. Qualitative Analysis of the Erosion Products of Sulfate Attack on Cement Concrete. The relationship between thermodynamic equilibrium constant and the Gibbs free energy of the reaction can be used to characterize the spontaneity of the generation of erosion products [27], written as equation (1). Based on Gibbs-Helmholtz equation [27], the relationship between Gibbs energy and temperature can be obtained, written as equation (2).

$$
\begin{aligned}
\Delta G^{\Theta} & =-\mathrm{RT} \ln K^{\Theta}, \\
\mathrm{d} \frac{\ln K^{\Theta}}{\mathrm{d} T} & =\frac{\Delta H^{\Theta}}{\mathrm{RT}^{2}},
\end{aligned}
$$

where $\Delta G^{\Theta}$ is standard Gibbs free energy, $\Delta H^{\Theta}$ is the standard enthalpy change of reaction, $T$ is temperature, $K^{\Theta}$ 
stands for thermodynamic equilibrium constant, and $R$ is ideal gas constant with a recommended value of $8.314 \mathrm{~J} /$ (mol.K).

Kirchhoff equation is usually used to describe the relationship between $\Delta H_{T}^{\Theta}$ and $T$, formulated as equation (3).

$$
\begin{aligned}
\mathrm{d}\left(\Delta H_{T}^{\Theta}\right) & =\Delta C_{p} \mathrm{~d} T \\
\Delta C_{p} & =\sum \Delta C_{p-\text { products }}-\sum \Delta C_{p-\text { reactants }} \\
& =\Delta a+\Delta b T+\Delta c T^{-2},
\end{aligned}
$$

where $\Delta C_{p \text {-products }}$ and $\Delta C_{p \text {-reactants }}$ are the differences in the specific heat at constant pressure between the products and reactants, respectively. $\Delta C_{p}$ is the difference in the heat capacity of the reaction, i.e., the difference between the sum of molar heat capacity under constant pressure of products and the sum of molar heat capacity under constant pressure of reactants. $\Delta a, \Delta b$, and $\Delta c$ are fitted constants, respectively.

The change of the molar heat capacity $C_{p}$ under constant pressure of products with temperature $T$ can be approximately described by equation (5). Hence, equation (4) can be represented as equation (6).

$$
\begin{aligned}
C_{p}= & A_{1}+A_{2} \times 10^{-3} T+A_{3} \times 10^{5} T^{-2}+A_{4} \times 10^{-6} T^{2} \\
& +A_{5} \times 10^{8} T^{-3}, \\
\Delta C_{p}= & \Delta A_{1}+\Delta A_{2} \times 10^{-3} T+\Delta A_{3} \times 10^{5} T^{-2}+\Delta A_{4} \\
& \times 10^{-6} T^{2}+\Delta A_{5} \times 10^{8} T^{-3},
\end{aligned}
$$

where $A_{1}, A_{2}, A_{3}, A_{4}$, and $A_{5}$ are the fitted data, respectively. $\Delta A_{1}, \Delta A_{2}, \Delta A_{3}, \Delta A_{4}$, and $\Delta A_{5}$ are the differences in the corresponding fitted data, respectively.

Integrating equations (3) and (5), the expression of the heat function of the reaction can be determined by [28]

$$
\begin{aligned}
\Delta H_{T}^{\Theta}= & \Delta A_{1} T+\frac{1}{2} \Delta A_{2} \times 10^{-3} T^{2}-\Delta A_{3} \times 10^{5} T^{-1}+\frac{1}{3} \Delta A_{4} \\
& \times 10^{-6} T^{3}-\frac{1}{2} \Delta A_{5} \times 10^{8} T^{-2} .
\end{aligned}
$$

If the standard molar formation heats of various substances at room temperature $\Delta H_{i, f, 298}^{\Theta}$ are known, the corresponding reaction heat of the system at $T=298 \mathrm{~K}$ can be determined as

$$
\Delta H_{T}^{\Theta}=\sum\left(n_{i} \Delta H_{i, f, 298}^{\Theta}\right)_{\text {reactants }}-\sum\left(n_{i} \Delta H_{i, f, 298}^{\Theta}\right)_{\text {products }} .
$$

Substituting the $\Delta H_{298}^{\Theta}$ calculated by equation (8) and $T=298 \mathrm{~K}$ into equation (7), the corresponding integration constant $A_{6}$ can be determined.

$$
\begin{aligned}
A_{6}= & \Delta H_{298}^{\Theta}-\Delta A_{1} T-\frac{1}{2} \Delta A_{2} \times 10^{-3} T^{2}+\Delta A_{3} \times 10^{5} T^{-1} \\
& -\frac{1}{3} \Delta A_{4} \times 10^{-6} T^{3}+\frac{1}{2} \Delta A_{5} \times 10^{8} T^{-2} .
\end{aligned}
$$

Using a numerical integrating of equation (2), the corresponding equation can be obtained as equation (10). Integrating equations (7) and (9), the standard Gibbs free energy of the reaction at $T$ can be expressed as equation (11).

$$
\begin{aligned}
\frac{\Delta G_{T}^{\Theta}}{T}= & -\int \frac{\Delta H_{T}^{\Theta}}{T^{2}} \mathrm{~d} T \\
\Delta G_{T}^{\Theta}= & -\Delta A_{1} T \ln T-\frac{1}{2} \Delta A_{2} \times 10^{-3} T^{2}-\frac{1}{2} \Delta A_{3} \times 10^{5} T^{-1} \\
& -\frac{1}{6} \Delta A_{4} \times 10^{-6} T^{3}-\frac{1}{6} \Delta A_{5} \times 10^{8} T^{-2}+A_{6}^{\prime} T+A_{6},
\end{aligned}
$$

where $A_{6}^{\prime}$ is the integration constant of the Gibbs-Helmholtz equation.

If the change of the standard enthalpy $\Delta H_{298}^{\Theta}$ and the thermal entropy $\Delta S_{298}^{\Theta}$ of the reaction at room temperature $(298 \mathrm{~K})$ are known, the corresponding standard Gibbs free energy of the reaction at $298 \mathrm{~K}$ can be determined by equation (12). Substituting the $\Delta G_{298}^{\Theta}$ calculated by equation (12) and $T=298 \mathrm{~K}$ into equation (11), the corresponding integration constant $A_{6}^{\prime}$ can be determined by equation (13).

$$
\begin{aligned}
\Delta G_{298}^{\Theta}= & \Delta H_{298}^{\Theta}-298 \Delta S_{298}^{\Theta}, \\
A_{6}^{\prime}= & \frac{\Delta G_{298}^{\Theta}}{T}+\Delta A_{1} \ln T+\frac{1}{2} \Delta A_{2} \times 10^{-3} T \\
& +\frac{1}{2} \Delta A_{3} \times 10^{5} T^{-2}+\frac{1}{6} \Delta A_{4} \times 10^{-6} T^{2} \\
& +\frac{1}{6} \Delta A_{5} \times 10^{8} T^{-3}-A_{6} T^{-1} .
\end{aligned}
$$

A conclusion can be drawn from equation (1) that the sulfate attack on cement concrete can be spontaneous when the Gibbs free energy is less than zero. Conversely, the reaction cannot progress spontaneously. Equation (11) shows the relationship between temperature and the Gibbs free energy of the erosion products generated during the sulfate attack on cement concrete, which can be used to reveal the direction of chemical reaction, existing condition and chemical stability of erosion products, and spontaneity of the erosion reaction.

2.2. Critical Ion Concentration of Erosion Products of the Sulfate Attack on Cement Concrete. Some researchers [27] proposed the expression of the thermodynamic equilibrium constant, written as

$$
\lg K_{\mathrm{eq}}^{\Theta}=A+B T+\frac{C}{T}+D \lg (T)+\frac{E}{T^{2}},
$$


where $K_{\text {eq }}^{\Theta}$ stands for the thermodynamic equilibrium constant at standard conditions. $A, B, C, D$, and $E$ are constant, respectively.

The main erosion products of sulfate attack on cement concrete may be gypsum, ettringite, and sulfate salt, $[29,30]$ and [31], and the corresponding reactions can be written as $[19,32]$

$$
\begin{aligned}
& \mathrm{Ca}_{(\mathrm{aq})}^{2+}+\mathrm{SO}_{4(\mathrm{aq})}^{2-} \underset{\text { Dissolve }}{\stackrel{\text { Crystallize }}{\rightleftharpoons}} \mathrm{CaSO}_{4(\mathrm{~s})} \\
& \mathrm{Ca}_{(\mathrm{aq})}^{2+}+\mathrm{SO}_{4(\mathrm{aq})}^{2-}+2 \mathrm{H}_{2} \mathrm{O}_{(\mathrm{l})} \stackrel{\text { Crystallize }}{\underset{\text { Dissolve }}{\rightleftharpoons}} \mathrm{CaSO}_{4} \cdot 2 \mathrm{H}_{2} \mathrm{O}_{(\mathrm{s})} \\
& 2 \mathrm{Na}_{(\mathrm{aq})}^{+}+\mathrm{SO}_{4(\mathrm{aq})}^{2-} \underset{\text { Dissolve }}{\stackrel{\text { Crystallize }}{\rightleftharpoons}} \mathrm{Na}_{2} \mathrm{SO}_{4(\mathrm{~s})} \\
& 2 \mathrm{Na}_{(\mathrm{aq})}^{+}+\mathrm{SO}_{4(\mathrm{aq})}^{2-}+10 \mathrm{H}_{2} \mathrm{O}_{(\mathrm{l})} \underset{\text { Dissolve }}{\stackrel{\text { Crystallize }}{\rightleftharpoons}} \mathrm{Na}_{2} \mathrm{SO}_{4} \cdot 10 \mathrm{H}_{2} \mathrm{O}_{(\mathrm{s})} \\
& 6 \mathrm{Ca}^{2+}+2 \mathrm{Al}^{3+}+3 \mathrm{SO}_{4}^{2-}+32 \mathrm{H}_{2} \mathrm{O}_{(\mathrm{l})} \underset{\text { Dissolve }}{\stackrel{\text { Crystallize }}{\rightleftharpoons}} 3 \mathrm{CaO} \cdot \mathrm{Al}_{2} \mathrm{O}_{3} \\
& \cdot 3 \mathrm{CaSO}_{4} \cdot 32 \mathrm{H}_{2} \mathrm{O}_{(\mathrm{s})}
\end{aligned}
$$

$$
\begin{aligned}
& \mathrm{CaSiO}_{3} \cdot \mathrm{CaSO}_{4} \cdot \mathrm{CaCO}_{3} \cdot 15 \mathrm{H}_{2} \mathrm{O}_{(\mathrm{s})}+3 \mathrm{H}^{+} \underset{\text { Dissolve }}{\stackrel{\text { Crystallize }}{\rightleftharpoons}} 3 \mathrm{Ca}^{2+} \\
& +\mathrm{SO}_{4}^{2-}+\mathrm{HCO}_{3}^{-}+\mathrm{H}_{4} \mathrm{SiO}_{4}+14 \mathrm{H}_{2} \mathrm{O}_{(\mathrm{l})}
\end{aligned}
$$

where subscripts s, aq, and 1 stand for solid state, ionic state in solution, and liquid, respectively.

Correspondingly, the decomposition reactions of the cement hydration products can be expressed as follows $[19,33,34]$ :

$$
\begin{aligned}
& \mathrm{Ca}(\mathrm{OH})_{2(\mathrm{~s})}+2 \mathrm{H}^{+} \rightleftharpoons \mathrm{Ca}^{2+}+2 \mathrm{H}_{2} \mathrm{O} \\
& \mathrm{C}_{3} \mathrm{AH}_{6(\mathrm{~s})}+12 \mathrm{H}^{+} \rightleftharpoons 2 \mathrm{Al}^{3+}+3 \mathrm{Ca}^{2+}+12 \mathrm{H}_{2} \mathrm{O} \\
& \mathrm{C}_{4} \mathrm{AH}_{13(\mathrm{~s})}+14 \mathrm{H}^{+} \rightleftharpoons 2 \mathrm{Al}^{3+}+4 \mathrm{Ca}^{2+}+20 \mathrm{H}_{2} \mathrm{O} \\
& \mathrm{C}-\mathrm{S}-\mathrm{H}(0.8)_{(\mathrm{s})}+1.6 \mathrm{H}^{+} \rightleftharpoons 0.34 \mathrm{H}_{2} \mathrm{O}+0.8 \mathrm{Ca}^{2+}+\mathrm{H}_{4} \mathrm{SiO}_{4} \\
& \text { C-S-H }(1.2)_{(\mathrm{s})}+2.4 \mathrm{H}^{+} \rightleftharpoons 1.26 \mathrm{H}_{2} \mathrm{O}+1.2 \mathrm{Ca}^{2+}+\mathrm{H}_{4} \mathrm{SiO}_{4} \\
& \mathrm{Ca}_{2} \mathrm{SiO}_{4(\mathrm{~s})}+4 \mathrm{H}^{+} \rightleftharpoons 2 \mathrm{Ca}^{2+}+\mathrm{H}_{4} \mathrm{SiO}_{4} \\
& \mathrm{Al}(\mathrm{OH})_{3(\mathrm{~s})}+3 \mathrm{H}^{+} \rightleftharpoons \mathrm{Al}^{3+}+3 \mathrm{H}_{2} \mathrm{O} \\
& \mathrm{Ca}_{6} \mathrm{Al}_{2}\left(\mathrm{SO}_{4}\right)_{3}(\mathrm{OH})_{12} \cdot 26 \mathrm{H}_{2} \mathrm{O}_{(\mathrm{s})}+12 \mathrm{H}^{+} \rightleftharpoons 2 \mathrm{Al}^{3+}+6 \mathrm{Ca}^{2+} \\
& +3 \mathrm{SO}_{4}^{2-}+38 \mathrm{H}_{2} \mathrm{O}
\end{aligned}
$$

The reference values recommended by researchers $[35,36]$ are listed in Table 1.

The above reaction equations can be formulated as equation (29), and the relationship between the thermodynamic equilibrium constant and concentration of different substances can be expressed as equation (30).

$$
\begin{aligned}
d D+e E & \rightleftharpoons g G+h H, \\
K_{\mathrm{eq}}^{\Theta} & =\frac{[G]^{g}[H]^{h}}{[D]^{d}[E]^{e}},
\end{aligned}
$$

where $[D],[E],[G]$, and $[H]$ mean the concentration of different substances, respectively. $d, e, g$, and $h$ are the stoichiometric numbers, respectively.

Combining equations (14) and (30), the formation conditions and the critical ion concentration of sulfate ion for the formation of erosion products can be determined based on the thermodynamic parameter of different substances in Table 1 .

\section{Experimental Procedure}

3.1. Raw Materials. Portland cement of P O. 32.5 class was produced by Pingtang Cement Plant of Hunan, and the polycarboxylic acid series of superplasticizer with solid content of $30 \%$ provided by Changsha Huangteng Chemical Technology Co., Ltd was used as a water reducer. ISO standard sand with a fineness modulus of 3.0 was produced by Xiamen Aisiou Standard Sand Co., Ltd. Local river sand with a fineness modulus of 2.9, continuous grading limestone gravel with grains sizes of $5 \mathrm{~mm} \sim 20 \mathrm{~mm}$, and tap water were used to prepare the specimens. Moreover, the industrial grade sodium sulfate with purity of $99 \%$ was purchased from market. The chemical composition and physical properties of cement are listed in Tables 2 and 3.

3.2. Specimen Preparation, Experimental Process, and Test Devices. According to Common Portland Cement and Test Methods for Water Requirement of Normal Consistency, Setting Time and Soundness of the Portland Cement [37, 38], the paste specimens of $40 \mathrm{~mm} \times 40 \mathrm{~mm} \times 160 \mathrm{~mm}$ were cast with a water to cement ratio of 0.28 and were used for XRD analysis. According to Method of Testing Cements-Determination of Strength, the mortar specimens of $40 \mathrm{~mm} \times 40 \mathrm{~mm} \times 160 \mathrm{~mm}$ were cast with a water: cement: sand ratio of $0.5: 1: 3$ by weight [39]. According to Standard for Test Method of Mechanical Properties on Ordinary Concrete [40], the concrete specimens of $100 \mathrm{~mm} \times 100 \mathrm{~mm} \times 300 \mathrm{~mm}$ were cast, and there are three specimens for each group. The C20 grade concrete was prepared with a weight ratio of cement: sand:limestone: water: water reducer of $305: 831: 1102: 158: 3.5$. All specimens were cured in standard curing pool at a temperature of $(20 \pm 1)^{\circ} \mathrm{C}$ and a relative humidity of $(95 \pm 3) \%$. The specimens were demolded after $24 \mathrm{~h}$ and cured in water for $28 \mathrm{~d}$ at a temperature of $(20 \pm 1)^{\circ} \mathrm{C}$. Subsequently, the specimens were taken out from water to carry out sulfate attack test. 
TABLE 1: Thermodynamic parameters of different substances.

\begin{tabular}{|c|c|c|c|c|c|}
\hline Items & A & $\mathrm{B}$ & $\mathrm{C}$ & $\mathrm{D}$ & $\mathrm{E}$ \\
\hline $\mathrm{CaSO}_{4} \cdot 2 \mathrm{H}_{2} \mathrm{O}_{(\mathrm{s})}$ & $1.62021439 e+3$ & $2.57234846 e-1$ & $-8.91506186 e+4$ & $-5.87385148 e+2$ & $5.34735206 e+6$ \\
\hline $\mathrm{CaSO}_{4(s)}$ & $1.61807826 e+3$ & $2.62044313 e-1$ & $-8.95853477 e+4$ & $-5.86632877 e+2$ & $5.35893242 e+6$ \\
\hline $\mathrm{CaSO}_{4(\mathrm{aq})}$ & $1.72034184 e+3$ & $2.65734992 e-1$ & $9.42553556 e+4$ & $-6.23563883 e+2$ & $5.49729959 e+6$ \\
\hline $\mathrm{Na}_{2} \mathrm{SO}_{4} \cdot 10 \mathrm{H}_{2} \mathrm{O}_{(\mathrm{s})}$ & $1.58837182 e+3$ & $2.31777424 e-1$ & $-8.43055786 e+4$ & $-5.78226172 e+2$ & $5.09260164 e+6$ \\
\hline $\mathrm{Na}_{2} \mathrm{SO}_{4(\mathrm{~S})}$ & $1.61633032 e+3$ & $2.53239679 e-1$ & $-8.98032147 e+4$ & $-5.86414685 e+2$ & $5.40049408 e+6$ \\
\hline $\mathrm{AFt}_{(\mathrm{s})} \mathrm{Ca}_{6} \mathrm{Al}_{2}\left(\mathrm{SO}_{4}\right)_{3}(\mathrm{OH})_{12} \cdot 26 \mathrm{H}_{2} \mathrm{O}$ & $-6.67460197 e+3$ & -1.04743390 & $3.78708023 e+5$ & $2.42662966 e+3$ & $-2.05189885 e+7$ \\
\hline $\mathrm{Ca}(\mathrm{OH})_{2(\mathrm{~s})}$ & $-2.84930557 e+2$ & $-4.47108160 e-2$ & $2.13801821 e+4$ & $1.04205027 e$ & $4252617 e+5$ \\
\hline $1(\mathrm{OH})_{3(\mathrm{~s})}$ & & $e-2$ & 2.97138 & & $11 e+6$ \\
\hline $\mathrm{JaAlO}_{2(\mathrm{aq})}$ & & & & & \\
\hline $\mathrm{AlO}_{2}^{-}$(aq) & $-1.78049448 e+2$ & $-2.68902416 e-2$ & $1.86721225 e+3$ & $6.68330936 e+1$ & $-7.50442968 e+5$ \\
\hline $\mathrm{H}_{2} \mathrm{O}_{(\mathrm{aq})}$ & -701.957319 & -0.112739992 & 36168.254 & 253.60128 & -2423273.06 \\
\hline $\mathrm{C}-\mathrm{S}-\mathrm{H}(0.8)_{(\mathrm{s})} \mathrm{Ca}_{0.8} \mathrm{SiO}_{2.8} \cdot 1.54 \mathrm{H}_{2} \mathrm{O}$ & & -3.6 & & 9.219313 & $25 e+5$ \\
\hline$-\mathrm{S}-\mathrm{H}(1.2)_{(\mathrm{s})} \mathrm{Ca}_{1.2} \mathrm{SiO}_{3.2} \cdot 2.06 \mathrm{H}_{2} \mathrm{O}$ & $-3.72034132 e+2$ & $-5.41579845 e-2$ & 2.398452 & $6559314 e+2$ & $83 e+5$ \\
\hline $\mathrm{C}-\mathrm{S}-\mathrm{H}(1.6)_{(\mathrm{s})} \mathrm{Ca}_{1.6} \mathrm{SiO}_{3.6} \cdot 2.58 \mathrm{H}_{2} \mathrm{O}$ & $-4.91723254 e+2$ & $-7.17628896 e-2$ & $3.25370146 e+4$ & $1.80399649 e+2$ & $-1.27964571 e+6$ \\
\hline $\mathrm{C}_{2} \mathrm{AH}_{8(\mathrm{~s})} \mathrm{Ca}_{2} \mathrm{Al}_{2} \mathrm{O}_{5} \cdot 8 \mathrm{H}_{2} \mathrm{O}$ & $-1.73467190 e+3$ & $-2.38046203 e-1$ & $1.10411145 e+5$ & $6.23227246 e+2$ & $-4.18576035 e+6$ \\
\hline $\mathrm{C}_{3} \mathrm{AH}_{6(\mathrm{~s})} \mathrm{Ca}_{3} \mathrm{Al}_{2}(\mathrm{OH})_{12}$ & & & & & $-4.61172146 e+6$ \\
\hline $\mathrm{CaSiO}_{3} \mathrm{CaSO}_{4} \mathrm{CaCO}_{3} \cdot 15 \mathrm{H}_{2} \mathrm{O}_{(\mathrm{s})}$ & $-2.76283310 e+3$ & $-4.32736383 e-1$ & $1.49848596 e+5$ & $1.00850740 e+3$ & $-8.52601737 e+6$ \\
\hline$\alpha-\mathrm{Ca}_{2} \mathrm{SiO}_{4(\mathrm{~s})}$ & $-5.26934036 e+2$ & $-8.67703839 e-2$ & $3.89768377 e+4$ & $1.92577860 e+2$ & $-1.36961546 e+6$ \\
\hline $\mathrm{CaSiO}_{3(\mathrm{~s})}$ & $-2.65453934 e+2$ & $-4.41966587 e-2$ & $1.77395216 e+4$ & $9.72523635 e+1$ & $-6.65653039 e+5$ \\
\hline
\end{tabular}

TABle 2: Chemical composition of cement (\%).

\begin{tabular}{lcccccccc}
\hline $\mathrm{CaO}$ & $\mathrm{SiO}_{2}$ & $\mathrm{Al}_{2} \mathrm{O}_{3}$ & $\mathrm{P}_{2} \mathrm{O}_{5}$ & $\mathrm{Fe}_{2} \mathrm{O}_{3}$ & $\mathrm{MgO}$ & $\mathrm{K}_{2} \mathrm{O}$ & $\mathrm{Na}_{2} \mathrm{O}$ & Loss \\
\hline 65.61 & 19.89 & 4.73 & 2.88 & 1.45 & 2.01 & 1.14 & 0.21 & 1.98 \\
\hline
\end{tabular}

Table 3: Physical properties of cement.

\begin{tabular}{lccccc}
\hline $\begin{array}{l}\text { Average diameter } \\
(\mu \mathrm{m})\end{array}$ & $\begin{array}{c}\text { Specific surface area } \\
\left(\mathrm{m}^{2} / \mathrm{kg}\right)\end{array}$ & $\begin{array}{c}\text { Bulk density } \\
\left(\mathrm{g} / \mathrm{cm}^{3}\right)\end{array}$ & $\begin{array}{c}\text { Initial setting time } \\
(\mathrm{min})\end{array}$ & $\begin{array}{c}\text { Final setting time } \\
(\mathrm{min})\end{array}$ & $\begin{array}{c}\text { Water requirement for standard } \\
\text { consistency }(\%)\end{array}$ \\
\hline 34.6 & 345.2 & 1.35 & 172 & 251 & 28 \\
\hline
\end{tabular}

The experimental process of the concrete attacked by sulfate was carried out as follows. Firstly, the sulfate solutions of different concentrations (i.e., 1\%, 5\%, 10\%, and saturated solution) were prepared, and various specimens were immersed into sulfate solution. In order to ensure the uniformity of sulfate solution, the distance of specimens was set as no less than $2 \mathrm{~cm}$. Then, the sealed solution box was covered with plastic film to prevent the water from evaporation. Moreover, the sulfate solution was changed once a week. Finally, the specimens were taken out from sulfate solution and dried at room temperature of $25^{\circ} \mathrm{C}$ and a relative humidity of $70 \%$ for 3 days when the erosion ages reached the setting time of 2 and 4 months. The flexural strength of the mortar and paste specimens was first tested, and then the corresponding compressive strength.

The preparation process of the samples for microproperties test was as follows. Firstly, the specimens reaching the sulfate attack age were cleaned with distilled water and broken into particles of $2 \mathrm{~mm} \sim 5 \mathrm{~mm}$. Secondly, the particles were immersed into alcohol for $24 \mathrm{~h}$ to terminate reaction. Then, the particles were dried at $60^{\circ} \mathrm{C}$ for $48 \mathrm{~h}$. Finally, the processed particles were placed and stored in a dryer. The proceeded particles containing surface were selected, and their cross-sections were sprayed with gold for ESEM-EDS analysis. The observed localization of the proceeded particle for ESEM-EDS analysis was near the outer surface of the cross-sections. In order to conduct the XRD analysis, the superficial region within $2 \mathrm{~mm}$ from cement sample surface was obtained and treated as mentioned above. Subsequently, the proceeded cement paste particles were ground to powder through 200 mesh, and the scanning step of XRD analysis was $0.02^{\circ}$. All samples were prepared and tested according to the equipment guide.

The main test devices were as follows. The Quanta-200 Environment Scanning Electronic Microscope (ESEM-EDS) produced by FTI Company of Czech Republic with an amplification of 600,000 times was used to measure the microstructure. The D/max-2550 X-ray diffraction (XRD) with the angular range of $5^{\circ} \sim 120^{\circ}$ and a minimum scanning step size of $0.01^{\circ}$ was used to carry out the phase analysis. The YAW-300D produced by Jinan Kesheng Test Equipment Co. Ltd. of China was used to measure the flexural and compressive strength of the specimens. The maximum compressive and flexural loads were $300 \mathrm{kN}$ and $10 \mathrm{kN}$, respectively. The corresponding loading rates of compressive and flexural strength were $(2.4 \pm 0.2) \mathrm{kN} / \mathrm{s}$ and $(50 \pm 10) \mathrm{N} / \mathrm{s}$, respectively. Moreover, the WAW-1000 electrohydraulic servo universal testing machine made by Shanghai Sansi Co. Ltd. of China was used to measure the compressive strength of the concrete. According to Standard for Test Method of 
Mechanical Properties on Ordinary Concrete [40], the corresponding loading rate was in the range of $0.3 \mathrm{MPa} /$ $\mathrm{s} \sim 0.55 \mathrm{MPa} / \mathrm{s}$.

\section{Results and Discussions}

4.1. Assessment of Erosion Products of Sulfate Attack on Cement Concrete. The main erosion products of sulfate attack on cement concrete may be gypsum, ettringite, sulfate salt, and so on. Therefore, the formation spontaneity of the above erosion products was deduced firstly based on the principles of chemical thermodynamics. Because the thermodynamics parameters of different erosion products were affected by environmental conditions remarkably, the thermodynamics parameters of different reactions for erosion products at different conditions including dry, humid, and water environment were calculated theoretically. The reactions of dihydrate gypsum and anhydrite, and mirabilite and thenardite can be written as follows (subscript (g) stands for the gaseous state) $[19,32,36]$.

$$
\begin{aligned}
\mathrm{CaSO}_{4(\mathrm{~s})}+2 \mathrm{H}_{2} \mathrm{O}_{(\mathrm{g})} & \rightleftharpoons \mathrm{CaSO}_{4} \cdot 2 \mathrm{H}_{2} \mathrm{O}_{(\mathrm{s})} \\
\mathrm{CaSO}_{4(\mathrm{~s})}+2 \mathrm{H}_{2} \mathrm{O}_{(\mathrm{l})} & \rightleftharpoons \mathrm{CaSO}_{4} \cdot 2 \mathrm{H}_{2} \mathrm{O}_{(\mathrm{s})} \\
\mathrm{Na}_{2} \mathrm{SO}_{4(\mathrm{~s})}+10 \mathrm{H}_{2} \mathrm{O}_{(\mathrm{g})} & \rightleftharpoons \mathrm{Na}_{2} \mathrm{SO}_{4} \cdot 10 \mathrm{H}_{2} \mathrm{O}_{(\mathrm{s})} \\
\mathrm{Na}_{2} \mathrm{SO}_{4(\mathrm{~s})}+10 \mathrm{H}_{2} \mathrm{O}_{(\mathrm{l})} & \rightleftharpoons \mathrm{Na}_{2} \mathrm{SO}_{4} \cdot 10 \mathrm{H}_{2} \mathrm{O}_{(\mathrm{s})}
\end{aligned}
$$

The corresponding thermodynamic parameters of different reactions can be determined based on equations (4) (13) and Table 4, as listed in Table 5. Moreover, the Gibbs free energy curves of various erosion products under different conditions as a function of temperature are plotted in Figure 1.

Figure 1(a) shows that the theoretical transformation temperature between dihydrate gypsum and anhydrite under humid and water conditions is about $91^{\circ} \mathrm{C}$; that is, the dihydrate gypsum can be spontaneously formed when the temperature is lower than $91^{\circ} \mathrm{C}$. However, the corresponding temperature under dry condition is about $56^{\circ} \mathrm{C}$; i.e., the dihydrate gypsum can be translated into anhydrite when the temperature exceeds $56^{\circ} \mathrm{C}$. Figure 1 (b) indicates that the theoretical transformation temperature between mirabilite and thenardite under dry condition is about $45^{\circ} \mathrm{C}$; however, it is about $88^{\circ} \mathrm{C}$ under humid and water conditions. From the above discussions, a conclusion can be drawn that the environment conditions have significant effects on the transformation of the crystals with combined water. Therefore, the environmental condition should be considered as an important factor of sulfate attack on cement concrete during the test process of sulfate attack and specimens' preparation. It is the theoretical transformation temperature curve based upon which the substances with or without crystal water would be converted. In Figure 1, the Gibbs free energy curves are calculated based on the theoretical transformation temperature of the substances without crystal water converted into the substances with crystal water. Because the theoretical calculated data do not consider the activity of substances, there exists a difference between the theoretical calculated results and the in-site measured data. The research [41] showed that the solubility of calcium sulfate at normal temperatures and pressures was about $0.2 \%$, and the temperature corresponding to the intersection of solubility curves of dihydrate gypsum and anhydrite was $42^{\circ} \mathrm{C}$ [42]. The above achievements accord well with the theoretical calculated data in Figure 1, which implies that equation (11) proposed by this study can be used to determine the mechanism of sulfate attack. Because all the sulfate attacks took place in the concrete pore solution, the deterioration mechanism and erosion products of sulfate attack reacting in solution were further investigated.

4.2. Numerical Analysis of Critical Concentration of Sulfate Ion of Different Erosion Products with Temperature. Calcium hydroxide $(\mathrm{CH})$ in cement and concrete has a significant effect on the thermodynamic equilibrium of various products, so the variation of critical concentration of $\left[\mathrm{OH}^{-}\right]$and $\left[\mathrm{Ca}^{2+}\right]$ with temperature is investigated firstly. Assuming the content of hydroxyl ion is generated by $\mathrm{CH}$ and dominated by $\mathrm{CH}$ saturated solution, the corresponding chemical equilibrium based on Hess's law can be expressed as follows [36]:

$$
\begin{aligned}
& \mathrm{Ca}(\mathrm{OH})_{2(\mathrm{~s})}+2 \mathrm{H}^{+}=\mathrm{Ca}^{2+}+2 \mathrm{H}_{2} \mathrm{O} \\
& \mathrm{H}_{2} \mathrm{O}=\mathrm{H}^{+}+\mathrm{OH}^{-} \\
& \mathrm{Ca}(\mathrm{OH})_{2(\mathrm{~s})}=\mathrm{Ca}^{2+}+2 \mathrm{OH}^{-}
\end{aligned}
$$

The corresponding thermodynamic equilibrium constant at standard conditions of the above reaction can be determined based on equation (1), written as

$$
\ln K^{\Theta}=\ln K_{1}^{\Theta}+2 \ln K_{2}^{\Theta} \text {. }
$$

Assuming the $\left[\mathrm{OH}^{-}\right]$in the system is generated by $\mathrm{Ca}(\mathrm{OH})_{2}$, the concentration of calcium ion is half of the hydroxyl ion. The concentration of hydroxyl ion with temperature can be determined based on equation (36), as shown in Figure 2. If the activity of condensed matters is set as 1 , the critical concentration of sulfate ion for the formation of dihydrate gypsum and anhydrite in equations (15) and (16) can be deduced on the basis of the calcium ion concentration and thermodynamic equilibrium constant, written as equations (37) and (38). The corresponding critical concentration curves of sulfate ions for the formation of dihydrate gypsum and anhydrite as a function of temperature are plotted in Figure 2.

$$
\begin{aligned}
& {\left[\mathrm{SO}_{4}^{2-}\right]=\frac{K_{\mathrm{CaSO}_{4} \cdot 2 \mathrm{H}_{2} \mathrm{O}}^{\Theta}}{a_{\left[\mathrm{Ca}^{2+}\right]}} \cdot c^{\Theta}} \\
& {\left[\mathrm{SO}_{4}^{2-}\right]=\frac{K_{\mathrm{CaSO}_{4}}^{\Theta}}{a_{\left[\mathrm{Ca}^{2+}\right]}} c^{\Theta}}
\end{aligned}
$$

As seen from Figure 2(a), the theoretical concentrations of $\left[\mathrm{Ca}^{2+}\right]$ and $\left[\mathrm{OH}^{-}\right]$corresponding to the thermodynamic 
TABLE 4: Thermodynamic parameters for different products.

\begin{tabular}{lcccccc}
\hline Items & $\Delta_{f} \mathrm{H}_{298}^{\Theta}(\mathrm{J} / \mathrm{mol})$ & $S_{298}^{\Theta}\left(\mathrm{J} / \mathrm{mol} \cdot \mathrm{K}^{-1}\right)$ & \multicolumn{3}{c}{$C_{\mathrm{p}}\left(\mathrm{J} / \mathrm{K} \cdot \mathrm{mol}^{-1}\right)$} \\
& -1434108 & 105.228 & 70.208 & 98.742 & 0 & $A_{3}$ \\
\hline $\mathrm{CaSO}_{4(\mathrm{~s})}$ & -2022629 & 194.138 & 91.379 & 317.984 & 0 & 0 \\
$\mathrm{CaSO}_{4} \cdot 2 \mathrm{H}_{2} \mathrm{O}_{(\mathrm{s})}$ & -241814 & 188.724 & 29.999 & 10.711 & 0.335 & 0 \\
$\mathrm{H}_{2} \mathrm{O}_{(\mathrm{g})}$ & -285840 & 69.94 & 33.1799 & 70.9205 & 11.1715 & 0 \\
$\mathrm{H}_{2} \mathrm{O}_{(\mathrm{l})}$ & -1387205 & 149.62 & 82.299 & 154.348 & 0 & 0 \\
$\mathrm{Na}_{2} \mathrm{SO}_{4(\mathrm{~s})}$ & -4327791 & 591.9 & 574.46 & 0 & 0 & 0 \\
$\mathrm{Na}_{2} \mathrm{SO}_{4} \cdot 10 \mathrm{H}_{2} \mathrm{O}_{(\mathrm{s})}$ & -982611 & 83.387 & 105.269 & 11.294 & -18.954 & 0 \\
$\mathrm{Ca}(\mathrm{OH})_{4(s)}$ & -428023 & 64.434 & 71.756 & -110.876 & 0 & 0 \\
$\mathrm{NaOH}_{(s)}$ & & & & 0 & 0 \\
\end{tabular}

TABle 5: Thermodynamic parameters of different reactions.

\begin{tabular}{|c|c|c|c|c|c|c|c|c|c|c|c|c|}
\hline Items & $\begin{array}{c}\Delta H_{298}^{\Theta} \\
(\mathrm{J} / \mathrm{mol})\end{array}$ & $\begin{array}{c}\Delta S_{298}^{\Theta} \\
\left(\mathrm{J} / \mathrm{mol}^{-1} \mathrm{~K}^{-1}\right)\end{array}$ & $\begin{array}{c}\Delta G_{298}^{\Theta} \\
(\mathrm{kJ} / \mathrm{mol})\end{array}$ & $\Delta A_{1}$ & $\Delta A_{2}$ & $\Delta A_{3}$ & $\Delta A_{4}$ & $\Delta A_{5}$ & $\begin{array}{c}\Delta C_{p, 298} \\
(\mathrm{~J} / \mathrm{K} \\
\left.\mathrm{mol}^{-1}\right)\end{array}$ & $\Delta A_{6}$ & $\Delta A_{6}^{\prime}$ & $\Delta A_{6}^{\prime \prime}$ \\
\hline $\begin{array}{l}\text { Equation } \\
\text { (31) }\end{array}$ & -104893 & 288.538 & -18908.676 & -38.827 & 197.82 & -0.67 & 0 & 0 & 19.369 & & 87.8375 & -126.665 \\
\hline $\begin{array}{l}\text { Equation } \\
\text { (32) }\end{array}$ & -16841 & -50.97 & -1651.94 & -45.1888 & 77.401 & -22.343 & 0 & 0 & -47.283 & -14309.1 & -216.018 & 170.829 \\
\hline $\begin{array}{l}\text { Equation } \\
\text { (33) }\end{array}$ & -522446 & -1444.96 & -91847.9 & 192.171 & -261.458 & -3.35 & 0 & 0 & 110.484 & -569227.9 & 2655.92 & -2463.75 \\
\hline $\begin{array}{l}\text { Equation } \\
\text { (34) }\end{array}$ & -82168 & -257.12 & -5564.24 & 160.362 & 863.553 & -111.715 & 0 & 0 & -222.776 & -129118.7 & 1136.64 & -976.278 \\
\hline
\end{tabular}

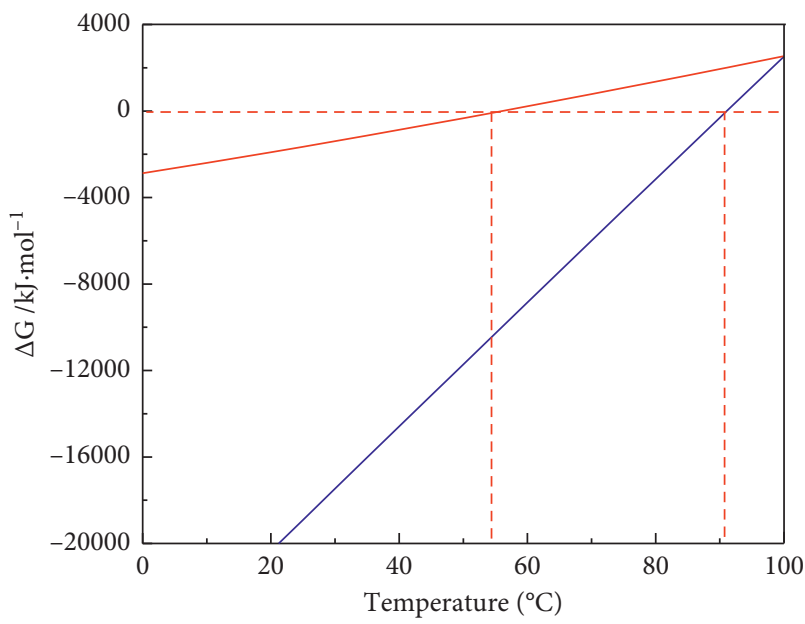

- Water and high humidity condition - Dry condition

(a)

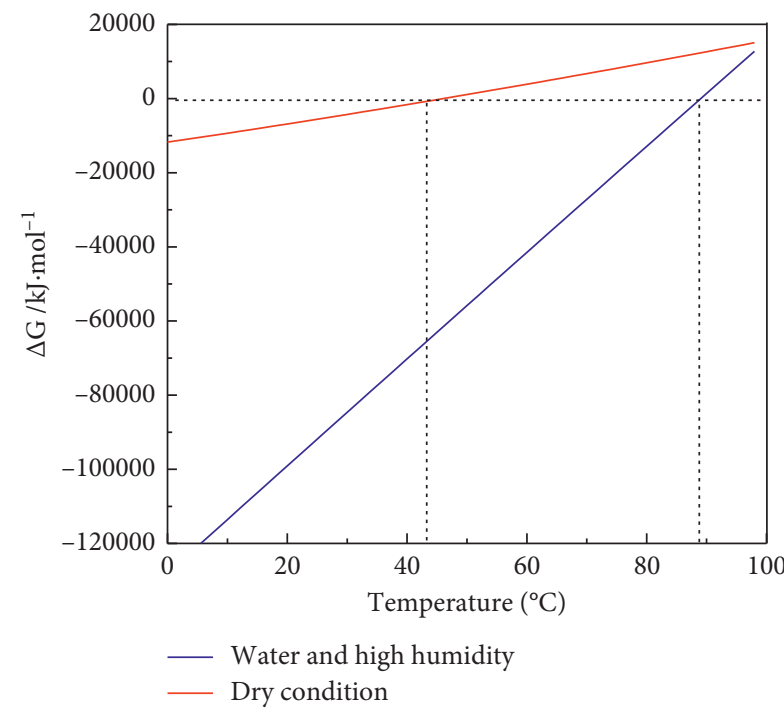

(b)

FiguRE 1: Gibbs free energy of various erosion products under different conditions versus temperature. (a) Dihydrate gypsum and anhydrite. (b) Mirabilite and thenardite.

equilibrium state of the system decrease with increase of the temperature, which accords well with the variation rule of actual solubility of $\mathrm{CH}$ with temperature. Figure 2(b) shows that there exists an intersection of the critical sulfate ion concentration curves of $\mathrm{CaSO}_{4}$ and $\mathrm{CaSO}_{4} \cdot 2 \mathrm{H}_{2} \mathrm{O}$ at about $42^{\circ} \mathrm{C}$. This indicates that $\mathrm{CaSO}_{4} \cdot 2 \mathrm{H}_{2} \mathrm{O}$ can be preferentially generated when the reaction temperature is less than $42^{\circ} \mathrm{C}$.
Conversely, it will be $\mathrm{CaSO}_{4}$. Figure 2 also reveals that the critical concentration of sulfate ion for the formation of $\mathrm{CaSO}_{4} \cdot 2 \mathrm{H}_{2} \mathrm{O}$ is more than $2.3 \times 10^{-3} \mathrm{~mol} / \mathrm{L}$, which is in accordance with the solubility of calcium sulfate (about 0.2 wt.\%) [41] under normal temperature and pressure. The change law of sulfate ion concentration with temperature also accords well with the actual solubility of gypsum, which 


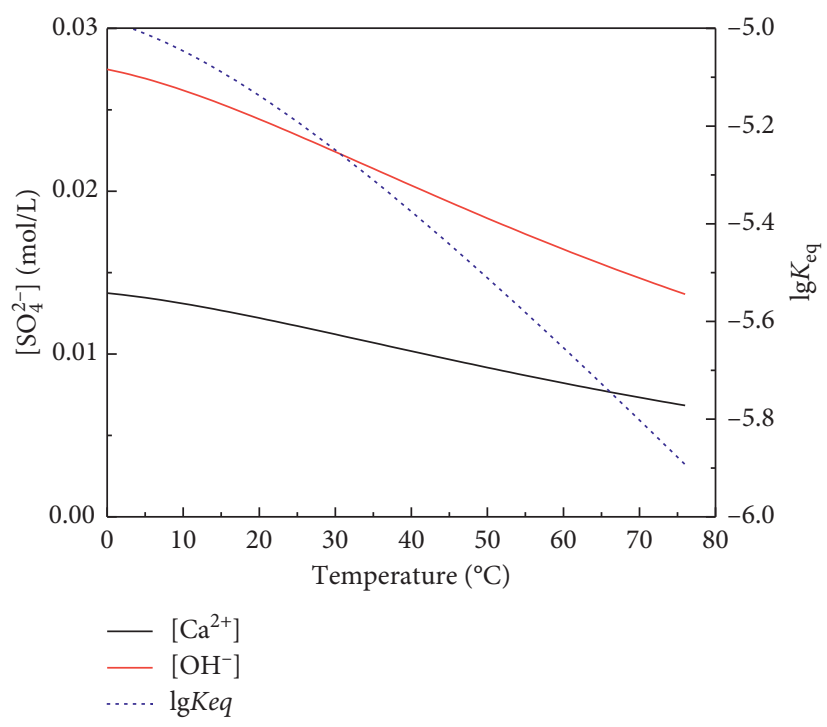

(a)

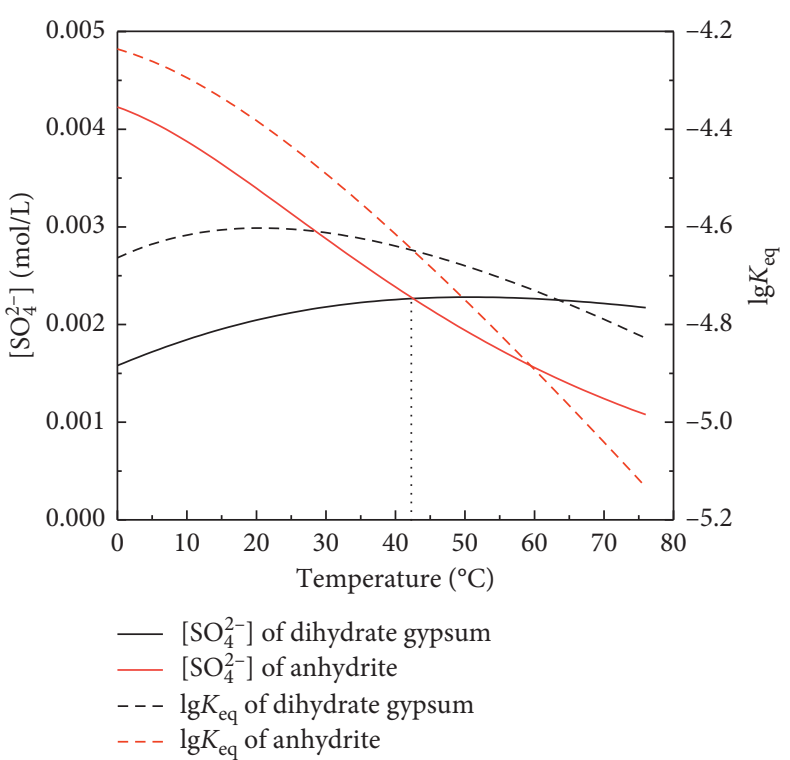

(b)

Figure 2: Curves of critical sulfate ion concentration and thermodynamic equilibrium constant with temperature. (a) $\mathrm{Ca}(\mathrm{OH})_{2}$. (b) $\mathrm{CaSO}_{4}$ and $\mathrm{CaSO}_{4} \cdot 2 \mathrm{H}_{2} \mathrm{O}$.

indicates that the principles of chemical thermodynamics can be used to determine the formation condition and critical concentration of various ions. Moreover, the logarithm values of the thermodynamic equilibrium constant in Figure 2 are all negative numbers, which implies that the Gibbs free energy of the reactions is less than zero. Therefore, the corresponding erosion reaction is spontaneous.
The variations of critical concentration of sulfate ion for the formation of $\mathrm{AFt}, \mathrm{AFm}$, and thaumasite $(\mathrm{CS} \overline{\mathrm{CS}} \mathrm{H})$ as a function of temperature were also investigated. Assuming the $\left[\mathrm{Al}^{3+}\right]$ generated by the decomposition of $\mathrm{C}_{3} \mathrm{AH}_{6}$ and $\mathrm{C}_{4} \mathrm{AH}_{13}$ can react with $\left[\mathrm{Ca}^{2+}\right]$ and $\left[\mathrm{SO}_{4}^{2-}\right]$, and the concentration of $\left[\mathrm{Ca}^{2+}\right]$ and $\left[\mathrm{OH}^{-}\right]$is also dominated by $\mathrm{Ca}(\mathrm{OH})_{2}$ solution, the chemical equations of $\mathrm{AFt}, \mathrm{AFm}$, and $\mathrm{CS} \overline{\mathrm{CS}} \mathrm{H}$ can be expressed as follows [36].

$$
\begin{aligned}
& \mathrm{CS} \overline{\mathrm{CS}} \mathrm{H}_{(\mathrm{s})}+3 \mathrm{H}^{+}=\mathrm{HCO}_{3}^{-}+3 \mathrm{Ca}^{2+}+\mathrm{SO}_{4}^{2-}+\mathrm{H}_{4} \mathrm{SiO}_{4}+14 \mathrm{H}_{2} \mathrm{O} \\
& \mathrm{CaCO}_{3(s)}+\mathrm{H}^{+}=\mathrm{HCO}_{3}^{-}+\mathrm{Ca}^{2+} \\
& \mathrm{CaSO}_{4} \cdot 2 \mathrm{H}_{2} \mathrm{O}_{(\mathrm{s})}+\mathrm{H}^{+}=\mathrm{Ca}^{2+}+\mathrm{SO}_{4}^{2-} \\
& \mathrm{CaSiO}_{3(\mathrm{~s})}+2 \mathrm{H}^{+}+\mathrm{H}_{2} \mathrm{O}_{(1)}=\mathrm{Ca}^{2+}+\mathrm{H}_{4} \mathrm{SiO}_{4(\mathrm{~s})} \\
& (1)-(2)-(3)-(4) \Longrightarrow \mathrm{CS} \overline{C S} H_{(s)}=\mathrm{CaCO}_{3(\mathrm{~s})}+\mathrm{CaSO}_{4} \cdot 2 \mathrm{H}_{2} \mathrm{O}_{(\mathrm{s})}+\mathrm{CaSiO}_{3(\mathrm{~s})}+13 \mathrm{H}_{2} \mathrm{O}_{(\mathrm{l})}
\end{aligned}
$$

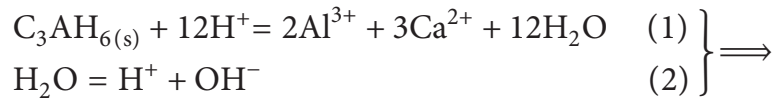

$$
\begin{aligned}
& (1)+12 \times(2) \Longrightarrow \mathrm{C}_{3} \mathrm{AH}_{6(\mathrm{~s})}=2 \mathrm{Al}^{3+}+3 \mathrm{Ca}^{2+}+12 \mathrm{OH}^{-}
\end{aligned}
$$

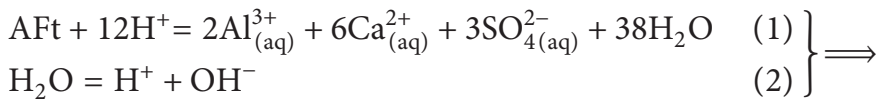

$$
\begin{aligned}
& (1)+12 \times(2) \Longrightarrow \mathrm{AFt}_{(\mathrm{s})}=2 \mathrm{Al}^{3+}+6 \mathrm{Ca}^{2+}+3 \mathrm{SO}_{4}^{2-}+12 \mathrm{OH}^{-}+26 \mathrm{H}_{2} \mathrm{O}
\end{aligned}
$$


The corresponding thermodynamic equilibrium constant at standard conditions of the reaction can be determined based on equation (1), written as follows:

$$
\begin{gathered}
K_{\mathrm{CS} \overline{\mathrm{C}} \mathrm{H}}^{\Theta}=\frac{a_{\left[\mathrm{HCO}_{3}^{-}\right]} \cdot a_{\left[\mathrm{Ca}^{2+}\right]}^{3} \cdot a_{\left[\mathrm{SO}_{4}^{2-}\right]}^{12} \cdot a_{\left[\mathrm{H}_{4} \mathrm{SiO}_{4}\right]} \cdot a_{\left[\mathrm{H}_{2} \mathrm{O}\right]}^{14}}{a_{[\mathrm{CS} \overline{\mathrm{C}} \mathrm{H}]} \cdot a_{\left[\mathrm{H}^{+}\right]}^{3}} \\
K_{\mathrm{C}_{3} \mathrm{AH}_{6}}^{\Theta} \cdot\left(K_{\mathrm{H}_{2} \mathrm{O}}^{\Theta}\right)^{12}=\frac{a_{\left[\mathrm{Al}^{3+}\right]}^{2} \cdot a_{\left[\mathrm{Ca}^{2+}\right]}^{3} \cdot a_{\left[\mathrm{OH}^{-}\right]}^{12}}{a_{\left[\mathrm{C}_{3} \mathrm{AH}_{6}\right]}} \\
K_{\mathrm{AFt}}^{\Theta} \cdot\left(K_{\mathrm{H}_{2} \mathrm{O}}^{\Theta}\right)^{12}=\frac{a_{\left[\mathrm{Al}^{3+}\right]}^{2} \cdot a_{\left[\mathrm{Ca}^{2+}\right]}^{6} \cdot a_{\left[\mathrm{H}_{2} \mathrm{O}\right]}^{26} \cdot a_{\left[\mathrm{SO}_{4}^{2-}\right]}^{3} \cdot a_{\left[\mathrm{OH}^{-}\right]}^{12}}{a_{[\mathrm{AFt}]}}
\end{gathered}
$$

Assuming the activity of condensed matter equals 1 , the corresponding activity of the sulfate ion for different erosion products can be written as follows:

$$
\begin{aligned}
& a_{\left[\mathrm{SO}_{4}^{2-}\right]}=\frac{K_{\mathrm{CS} \overline{\mathrm{C}} \mathrm{H}}^{\Theta}}{a_{\left[\mathrm{Ca}^{2+}\right]}} \\
& a_{\left[\mathrm{SO}_{4}^{2-}\right]}=\frac{1}{a_{\left[\mathrm{Ca}^{2+}\right]}} \sqrt[3]{\frac{K_{\mathrm{AFt}}^{\Theta}}{K_{\mathrm{C}_{3} \mathrm{AH}_{6}}}}
\end{aligned}
$$

Simultaneously, the corresponding activity of the critical sulfate ion for AFt generated by $\mathrm{C}_{4} \mathrm{AH}_{13}$ can be represented as follows:

$$
a_{\left[\mathrm{SO}_{4}^{2-}\right]}=\sqrt[3]{\frac{K_{\mathrm{AFt}}^{\Theta} \cdot a_{\left[\mathrm{OH}^{-}\right]}^{2}}{K_{\mathrm{C}_{4} \mathrm{AH}_{13}}^{\Theta} \cdot\left(K_{\mathrm{H}_{2} \mathrm{O}}^{\Theta}\right)^{2} \cdot a_{\left[\mathrm{Ca}^{2+}\right]}^{2}}}
$$

If the erosion product of sulfate attack on cement and concrete is $\mathrm{AFm}$ which was generated by $\left[\mathrm{Al}^{3+}\right]$ decomposed by $\mathrm{C}_{3} \mathrm{AH}_{6}$ and $\mathrm{C}_{4} \mathrm{AH}_{13}$, the corresponding activity of the sulfate ion can be written as follows:

$$
\begin{aligned}
& a_{\left[\mathrm{SO}_{4}^{2-}\right]}=\frac{K_{\mathrm{AFm}}^{\Theta}}{K_{\mathrm{C}_{3} \mathrm{AH}}^{\Theta} \cdot a_{\left[\mathrm{Ca}^{2+}\right]}} \\
& a_{\left[\mathrm{SO}_{4}^{2-}\right]}=\frac{K_{\mathrm{AFm}}^{\Theta} \cdot a_{\left[\mathrm{OH}^{-}\right]}^{2}}{K_{\mathrm{C}_{4} \mathrm{AH}_{13}}^{\Theta} \cdot\left(K_{\mathrm{H}_{2} \mathrm{O}}^{\Theta}\right)^{2}}
\end{aligned}
$$

The critical concentrations of sulfate ion for different erosion products calculated by equations (45) (49) as a function of temperature are plotted in Figure 3.

As seen from Figure 3(a), the upper limit temperature for $\operatorname{CS} \bar{C} \bar{S} H$ to exist steadily is $44^{\circ} \mathrm{C}$. Once the system temperature is larger than this temperature, the $\operatorname{CS} \overline{\mathrm{C}} \overline{\mathrm{S}} \mathrm{H}$ may be decomposed. Simultaneously, the critical concentration of sulfate ion for the formation of $\operatorname{CS} \bar{C} \bar{S} H$ is about $0.0023 \mathrm{~mol} / \mathrm{L}$. The above results change the traditional viewpoint that $\operatorname{CS} \bar{C} \bar{S} H$ can only exist in low temperature [24] and provide theoretical support for the formation of $\operatorname{CS} \overline{\mathrm{C}} \overline{\mathrm{S}} \mathrm{H}$ under room temperature. Figure 3(b) shows that temperature and types of calcium aluminate hydrate have significant effects on the critical concentration of sulfate ion for the formation of AFt and AFm. Compared with $\mathrm{C}_{4} \mathrm{AH}_{13}$, the $\mathrm{C}_{3} \mathrm{AH}_{6}$ reacts more easily with sulfate ion at room temperature, and the corresponding critical concentration of sulfate ion is also lower. Figure 3 also reveals that the critical concentration of sulfate ion for the formation of $\mathrm{AFt}$ and AFm is lower than that of the gypsum, which implies that the AFt and AFm can be generated preferentially with better thermostability [43]. It is also the reason that the early strength of Portland cement can be enhanced by adding gypsum as well as the improvement in the finial and initial setting time.

Integrating equations (46) and (48), the critical concentration of sulfate ion for the transformation between $\mathrm{AFt}$ and $\mathrm{AFm}$ generated by $\mathrm{C}_{3} \mathrm{AH}_{6}$ can be expressed as equation (50). The theoretical thermodynamic equilibrium constant and sulfate ion concentration as a function of temperature are plotted in Figure 4.

$$
a_{\left[\mathrm{SO}_{4}^{2-}\right]}=\frac{1}{a_{\left[\mathrm{Ca}^{2+}\right]}} \sqrt{\frac{K_{\mathrm{AFt}}^{\Theta}}{K_{\mathrm{AFm}}^{\Theta}}}
$$

Figure 4(a) shows that the thermodynamic equilibrium constant of the AFt and AFm increases with temperature, and that of the AFm is larger. The critical concentration of sulfate ion corresponding to the transformation between them at room temperature is very low, but its variation becomes more significant when the temperature is higher than $40^{\circ} \mathrm{C}$. In general, the thermodynamic equilibrium constant of the AFt is less than that of the AFm. However, their thermodynamic equilibrium constants show the cubic and linear function relationship with the concentration of sulfate ion, respectively. Hence, the AFm can be preferentially generated under a low concentration of sulfate ion. The subsequent results are the decrease of sulfate ion concentration and the destruction of the thermodynamic equilibrium state, which may result in the decomposition of the AFt. Therefore, the AFt and AFm can transform each other and reach a new thermodynamic equilibrium state under a certain sulfate ion concentration. It may be related to the thermodynamic stability of the $\mathrm{AFt}$, as shown in Figure 4(b). It can be seen from Figure 4(b) that the thermodynamic stability of the AFt is about $97^{\circ} \mathrm{C}$; that is, the AFt may be decomposed when the system temperature is higher than the critical temperature. However, Lawrence [12] pointed out that the measured decomposition temperature of the AFt was about $60^{\circ} \mathrm{C} \sim 70^{\circ} \mathrm{C}$. The difference may be due to the fact that theoretical results do not consider the effect of activity of various products.

Some researches $[44,45]$ revealed the relationship of thenardite, mirabilite, and solution, expressed as follows:

$$
\begin{aligned}
& y=1-2.304 x-14.618 x^{2}, \\
& x=a_{t r} \cdot \exp (b \cdot T),
\end{aligned}
$$




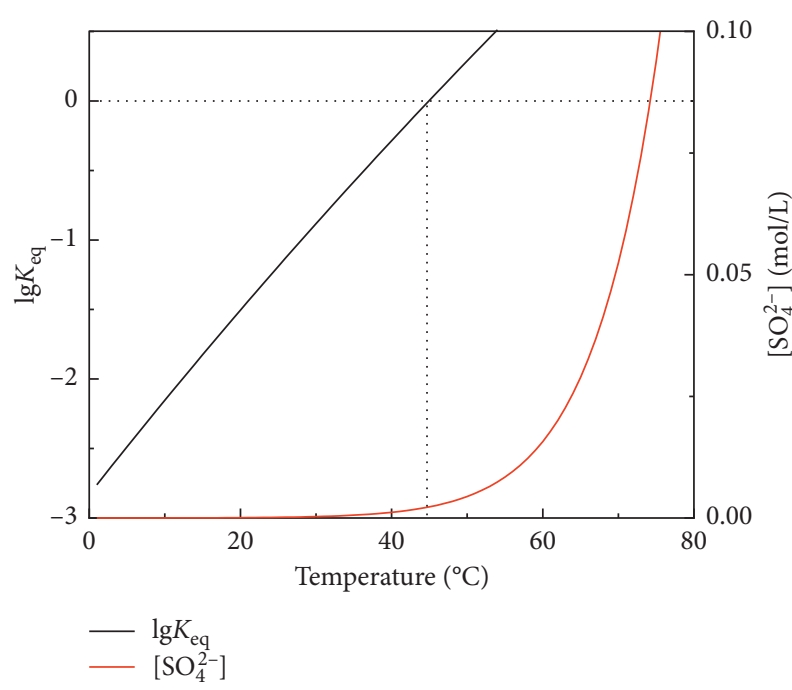

(a)

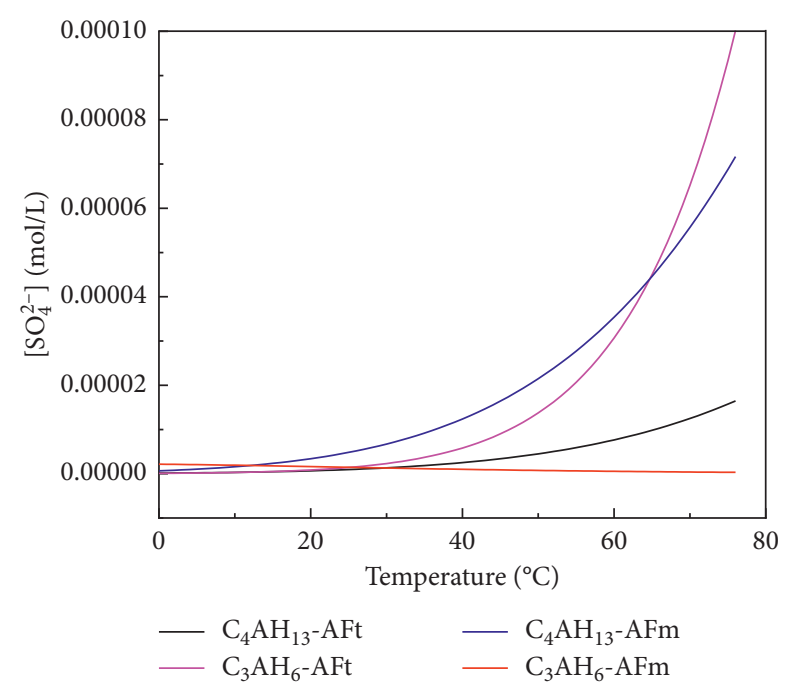

(b)

FIGURE 3: Variation curves of critical ions for different erosion products in system versus temperature. (a)CSCSH. (b) AFt and AFm.

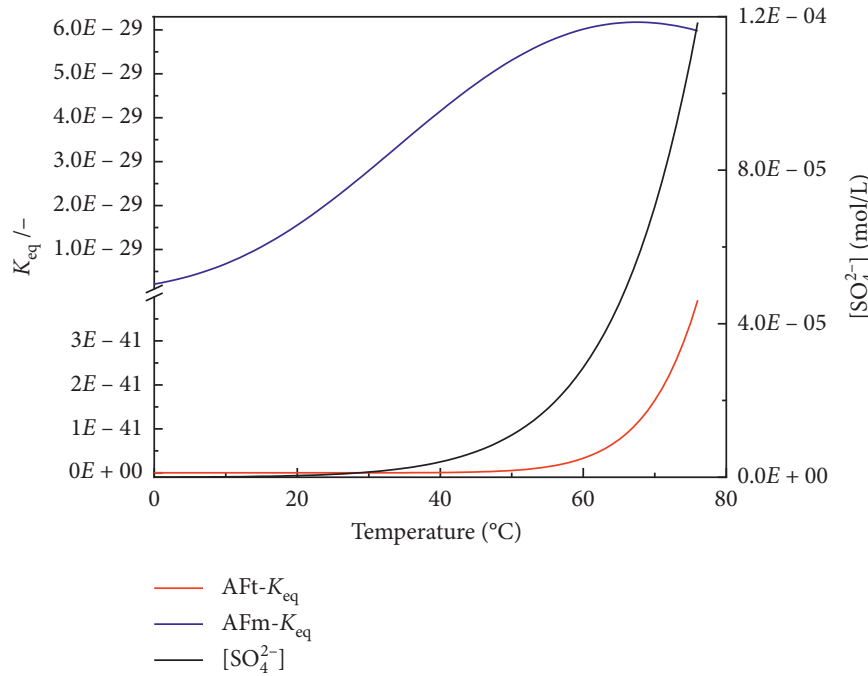

(a)

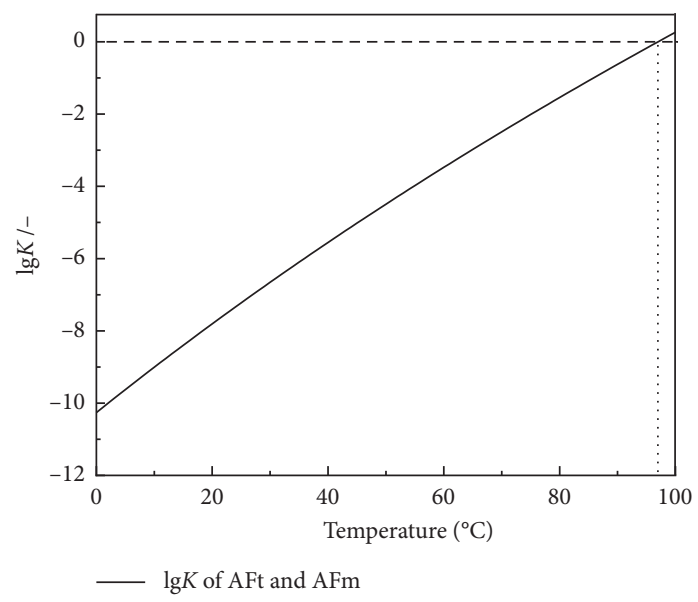

(b)

FIgURE 4: Curves of thermodynamic equilibrium constant and critical concentration of sulfate ion versus temperature. (a) Thermodynamic equilibrium constant and sulfate ion concentration. (b) Thermostability of the AFt and AFm.

where $T$ is the temperature, $y$ is the activity of liquid water, and $x$ stands for the mole fraction of sodium sulfate solution. $a_{t r}$ and $b$ are the fitted constants, respectively, and the recommended values are listed in Table 6.

The crystal transition point of $\mathrm{Na}_{2} \mathrm{SO}_{4} \cdot 10 \mathrm{H}_{2} \mathrm{O}$ and $\mathrm{Na}_{2} \mathrm{SO}_{4}$ can be determined based on equations (51) and (52), and the corresponding phase spectrum and solubility of sodium sulfate are plotted in Figure 5.

As seen from Figure 5, the crystal transition temperature between $\mathrm{Na}_{2} \mathrm{SO}_{4}$ and $\mathrm{Na}_{2} \mathrm{SO}_{4} \cdot 10 \mathrm{H}_{2} \mathrm{O}$ is about $32.4^{\circ} \mathrm{C}$; that is, the $\mathrm{Na}_{2} \mathrm{SO}_{4}$ may be crystallized from saturated solution when the temperature is higher than $32.4^{\circ} \mathrm{C}$. Correspondingly, the $\mathrm{Na}_{2} \mathrm{SO}_{4} \cdot 10 \mathrm{H}_{2} \mathrm{O}$ is the thermodynamical stable phase under high humidity and temperature lower than $32.4^{\circ} \mathrm{C}$. Conversely, the $\mathrm{Na}_{2} \mathrm{SO}_{4}$ salt may be crystallized under a lower temperature and humidity conditions. Although the solubility of sodium sulfate increases with the increase of the temperature, it gradually decreases when the temperature exceeds $32.4^{\circ} \mathrm{C}$, as shown in Figure 5. A conclusion can be drawn from the above discussion that the types and solubility of sodium sulfate are closely related to the temperature and relative humidity. Therefore, the types of erosion products in cement and concrete attacked by sulfate, i.e., $\mathrm{Na}_{2} \mathrm{SO}_{4}$ and $\mathrm{Na}_{2} \mathrm{SO}_{4} \cdot 10 \mathrm{H}_{2} \mathrm{O}$, are related to the reaction conditions; that is, they can transform each other and even coexist at a certain condition. The above theoretical deduction changes the traditional perception of the existence of single salt crystals of $\mathrm{Na}_{2} \mathrm{SO}_{4}$ and $\mathrm{Na}_{2} \mathrm{SO}_{4} \cdot 10 \mathrm{H}_{2} \mathrm{O}$. 
TABle 6: Value of the fitted data.

\begin{tabular}{lcc}
\hline Items & $a_{t r}$ & $b$ \\
\hline $\mathrm{Na}_{2} \mathrm{SO}_{4}$ & 0.11322 & -0.0024978 \\
$\mathrm{Na}_{2} \mathrm{SO}_{4} \cdot 10 \mathrm{H}_{2} \mathrm{O}$ & $4.3751 e-11$ & 0.068435 \\
\hline
\end{tabular}

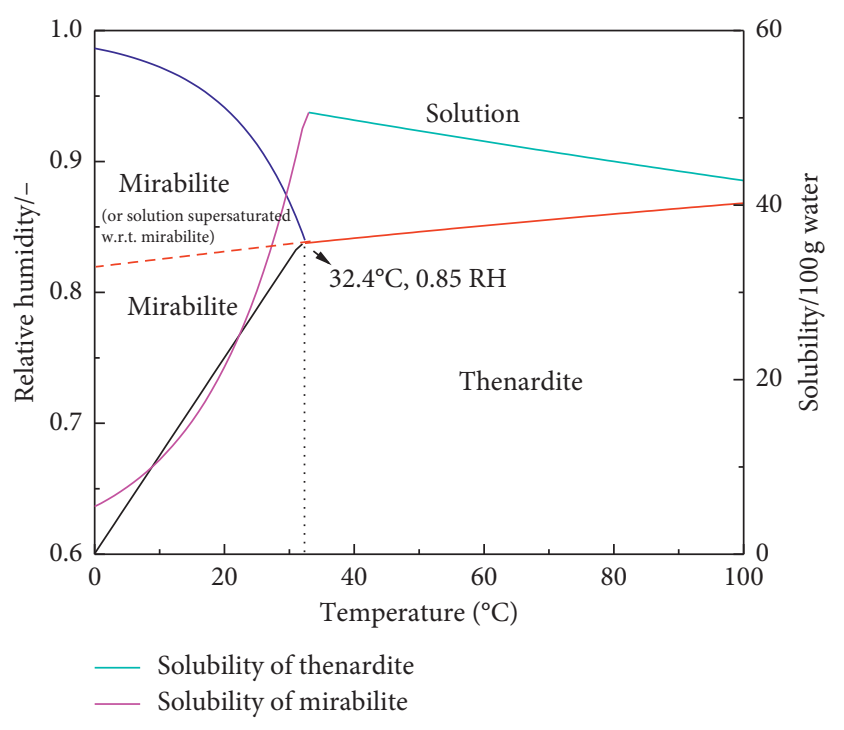

Figure 5: Phase spectrum and solubility of sodium sulfate.

Moreover, the critical concentration of sulfate ion for the formation of different erosion products can be determined based on the solubility curve in Figure 5, which provides theoretical support for the types and existence conditions of erosion products in cement.

To sum up, the generation of erosion products in cement is related to temperature, relative humidity, and sulfate ion concentration, and these factors affect each other. Among them, the $\left[\mathrm{SO}_{4}^{2-}\right]$ is one of the most important factors. The dihydrate gypsum is preferentially generated when the temperature is less than $42^{\circ} \mathrm{C}$ and $\left[\mathrm{SO}_{4}^{2-}\right]$ concentration is more than $2.3 \times 10^{-3} \mathrm{~mol} / \mathrm{L}$. However, the corresponding formation concentration of anhydrite is more than $4.2 \times 10^{-3} \mathrm{~mol} / \mathrm{L}$, and the temperature is larger than $42^{\circ} \mathrm{C}$. The theoretical thermodynamic stable temperature of AFt is about $97^{\circ} \mathrm{C}$, and the critical concentration of sulfate ion for the AFt is no less than $2.8 \times 10^{-3} \mathrm{~mol} / \mathrm{L}$. The mirabilite and thenardite may be generated when the concentration of sulfate ion is more than $1.5 \times 10^{-3} \mathrm{~mol} / \mathrm{L}$. The mirabilite can be spontaneously crystallized when the temperature is less than $32.4^{\circ} \mathrm{C}$. Moreover, the thaumasite can be formed when the temperature is less than $44^{\circ} \mathrm{C}$ and $\left[\mathrm{SO}_{4}^{2-}\right]$ concentration is more than $0.0023 \mathrm{~mol} / \mathrm{L}$. The above theoretical results accord well with the recommended value proposed by some researchers [46-48]; however, because the theoretical results do not consider the effect of activity of various products and the coupled effects of ions in system, it is a little bit different from that (less than $20^{\circ} \mathrm{C}$ ) reported by Blanco et al. [24]. The above results imply that the erosion products in cement attacked by different sulfate conditions can be determined by the principles of chemical thermodynamics, which provides theoretical support for the determination of erosion products in cement concrete.

\subsection{ESEM-EDS and XRD Analysis of Sulfate Attack on Cement} Concrete. In order to verify the rationality of the above theoretical calculation, the sulfate attack on cement and concrete was studied. The theoretical formation conditions including temperature and critical concentration of sulfate ion were all based on ideal solution; the activity of various ions and erosion products was not considered. Therefore, there would be a difference between theoretical calculation results and actual values. In order to determine the concentration range of sulfate concentration of different erosion products, the sulfate solution of different concentrations was prepared to conduct sulfate attack, i.e., $1 \%, 5 \%, 10 \%, 20 \%$, and saturated solution. Figure 6 shows the ESEM-EDS spectra of microstructure, types, and morphology of erosion products of cement concrete attacked by sulfate solution of different concentrations for 4 months.

Figure 6 shows that the microstructure, types, and morphology of substances of the specimens before and after sulfate attack are different. As seen from Figure 6(a), the major hydration products of the unattacked specimen are hexagonal plate-like calcium hydroxide $(\mathrm{CH})$, needle-like ettringite (AFt), flocculent and gelatinous calcium silicate hydrate $(\mathrm{C}-\mathrm{S}-\mathrm{H})$, and calcium aluminate hydrate $(\mathrm{C}-\mathrm{A}-\mathrm{H})$. Moreover, some micro pores and cracks can also be observed. With the increase of sulfate solution concentration (i.e., $1 \%$ and $5 \%$ ), plenty of rod-like AFt with a larger diameter-length ratio is generated in system, and the amount of hexagonal plate-like $\mathrm{CH}$ decreases, as shown in Figures 6(b) and 6(c). Some plate-like erosion products can be observed from the specimen attacked by $10 \%$ sulfate solution, which may be dihydrate gypsum or the partially corroded $\mathrm{CH}$, as shown in Figure 6(d). Moreover, plenty of dendritic and fibriform erosion products are observed in specific region of the specimen, as shown in Figure 6(e). The EDS analysis indicates that the major elements are $\mathrm{Ca}, \mathrm{Si}, \mathrm{O}$, and $\mathrm{S}$, which may be considered as the residual skeleton of $\mathrm{C}-\mathrm{S}-\mathrm{H}$ based on its morphology and characteristic, as shown in Figure 6(f). The higher the sulfate solution concentration, the more excellent the crystallinity of granular sulfate salt and plate-like erosion products, as shown in Figures 6(g) and 6(h). The EDS analysis indicates that the major elements are $\mathrm{Ca}, \mathrm{O}$, and $\mathrm{S}$, which may be dihydrate gypsum based on the characteristic of morphology, as shown in Figure 6(i). The concentration range of sulfate ion for the formation of erosion products in Figure 6 accords well with the theoretical calculated value in Section 4.2, which implies that the mechanism of sulfate attack on cement concrete can be represented by the principles of chemical thermodynamics. Moreover, the amount of hydration products including $\mathrm{CH}$, $\mathrm{C}-\mathrm{S}-\mathrm{H}$, and $\mathrm{C}-\mathrm{A}-\mathrm{H}$ in the specimens attacked by sulfate is reduced, which may be due to the fact that the sulfate attack reduces $\mathrm{pH}$ value, destroys thermodynamic equilibrium state, and accordingly results in the decomposition of hydration products. It can be seen that, compared with the microstructure of specimens attacked by sulfate solution of 


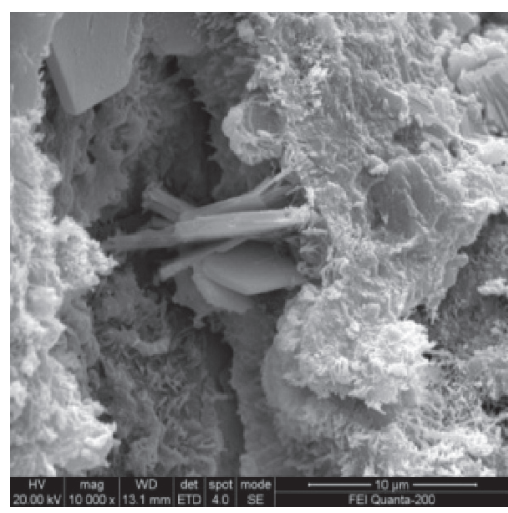

(a)

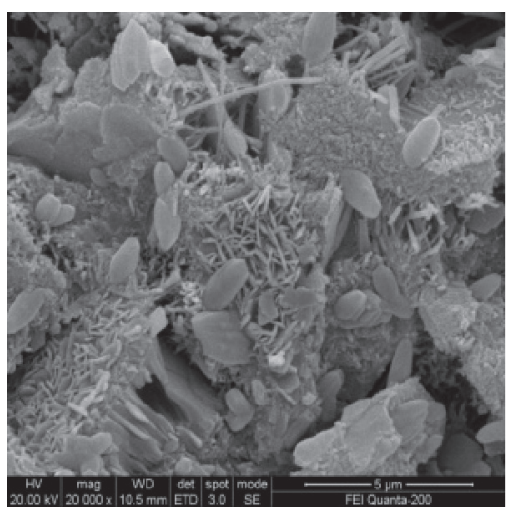

(d)

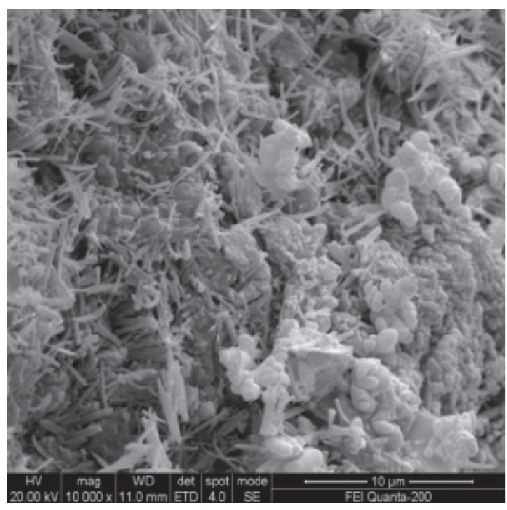

(g)

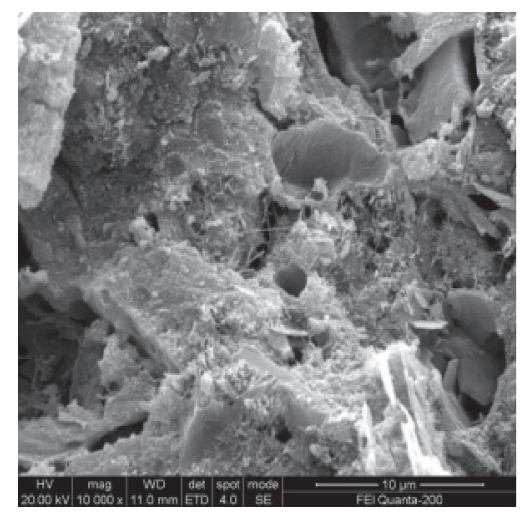

(b)

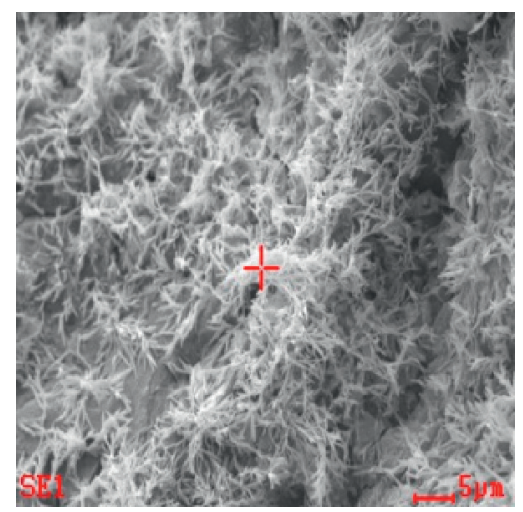

(e)

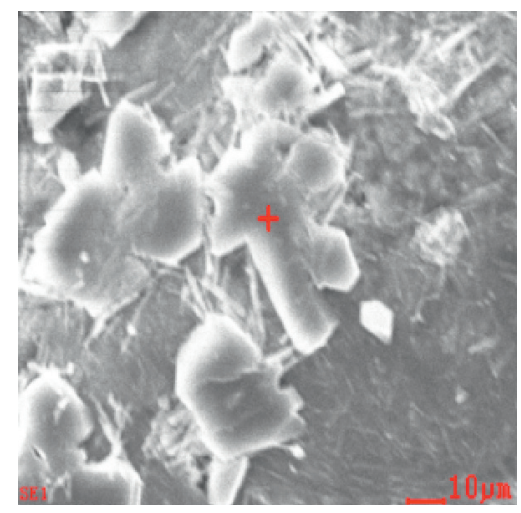

(h)

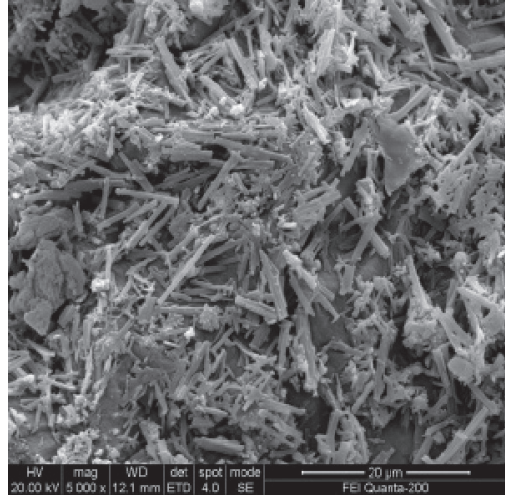

(c)

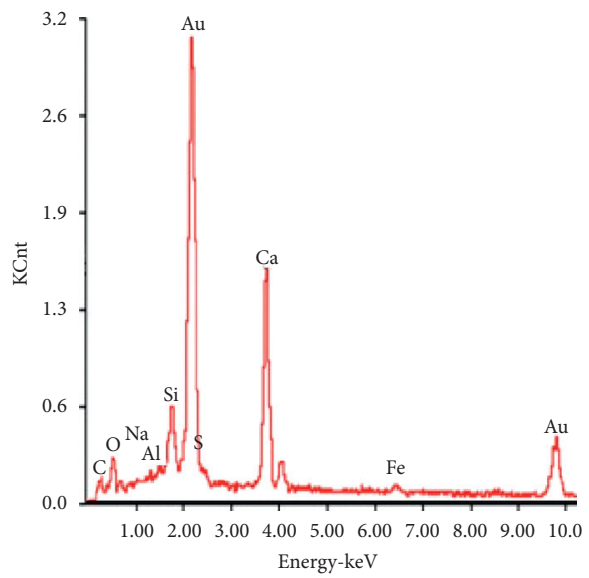

(f)

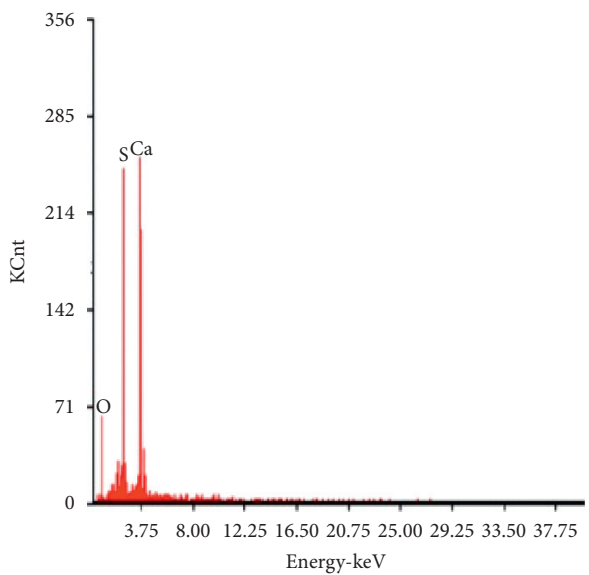

(i)

FIGURE 6: ESEM-EDS spectra of cement and concrete attacked by sulfate solution of different concentrations. (a) Non attacked. (b) $1 \%$. (c) $5 \%$. (d) $10 \%$. (e) $10 \%$. (f) EDS analysis. (g) 20\%. (h) Saturated solution. (i) EDS analysis.

different concentrations, the microstructure of the specimen attacked by $1 \%$ sulfate solution becomes denser, which is caused by the generation of expansive substances of the AFt and AFm which fill in pores and reduce part of the porosity. Therefore, it has a positive effect on the performances of the specimens attacked by low sulfate solution concentration. However, if the sulfate attack reduces $\mathrm{pH}$ value of the system and causes the decomposition of hydration products and deterioration of microstructure, it will have a negative effect on the performance of the specimens.

In order to investigate the effect of sulfate solution concentration on the phase composition of cement concrete, the XRD spectra of the cement attacked by sulfate for 4 months were tested, as shown in Figure 7.

As seen from Figure 7, there exist some significant differences in the erosion products' spectra before and after 


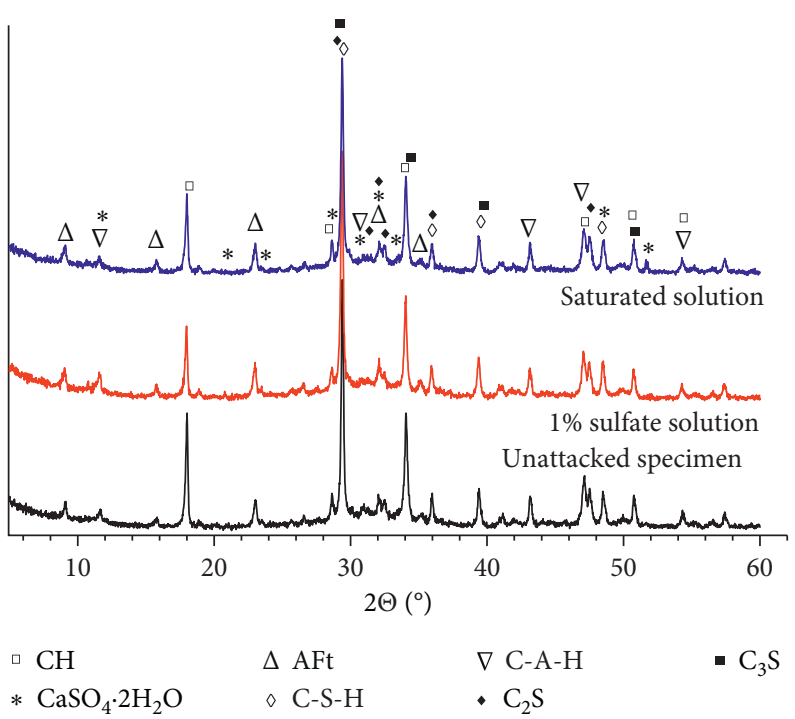

FIGURE 7: XRD spectra of phase composition of specimens attacked by sulfate solution.

sulfate attack, shown as the appearance and disappearance of some diffraction peaks, and variations of intensity and width of diffraction peaks. Based on the characteristic diffraction peak of the substances, it can be seen that the major hydration products of the specimens without sulfate attacked are calcium hydroxide $(\mathrm{CH})$, calcium aluminate hydrate $(\mathrm{C}$ $\mathrm{A}-\mathrm{H})$, calcium silicate hydrate (C-S-H), unhydrated tricalcium silicate $\left(\mathrm{C}_{3} \mathrm{~S}\right)$, and dicalcium silicate $\left(\mathrm{C}_{2} \mathrm{~S}\right)$. Their diffraction peaks' intensity is stronger and the width is narrower. After being attacked by sulfate solution of different concentrations, i.e., $1 \%$ and saturated sulfate solution, some diffraction peaks' intensity of the hydration products including $\mathrm{CH}, \mathrm{C}-\mathrm{A}-\mathrm{H}$, and $\mathrm{C}-\mathrm{S}-\mathrm{H}$ decreases, and the characteristic diffraction peaks' intensity belonging to the AFt enhances. Moreover, some new diffraction peaks corresponding to the gypsum appear. This is due to the fact that the sulfate ion reacts with hydration products of $\mathrm{CH}$ and $\mathrm{C}-\mathrm{A}-\mathrm{H}$ and is generated into AFt and gypsum. Furthermore, some characteristic diffraction peaks' intensity weakens, which may be caused by the decrease of $\mathrm{pH}$ value due to reaction of the sulfate ion with $\mathrm{CH}$. Therefore, the thermodynamic equilibrium state of system is destroyed and results in the decomposition of cementitious hydration products. The variation of diffraction peaks of the specimens before and after sulfate attack accords well with the results in Figure 6. No diffraction speaks of mirabilite and thenardite are observed in Figure 7, which may be due to the fact that the sulfate ion intruding into specimen is reacted, and the dehydration of mirabilite resulted from the preparation method of XRD analysis.

4.4. Variation of Mechanical Properties of the Specimens Attacked by Sulfate. The microstructure, types, and morphology of erosion products and phase compositions of the specimens can be affected by sulfate attack. In order to investigate the effects of sulfate attack on macro properties of the specimens, the mechanical properties of the specimens attacked by sulfate solution of different concentrations and erosion ages (i.e., 2 and 4 months) were investigated, as shown in Figure 8.

As seen from Figure 8, the mechanical properties of the specimens attacked by sulfate for 2 months first increase and then decrease with the increase of sulfate solution concentration, and the corresponding strength is larger than that of the unattacked specimens. Compared with mortar and concrete, the variation of the paste strength is more significant. There may be two primary reasons for the confusion. First, the water to cement ratio is lower, so the porosity of cement paste specimen is less. Some sulfate ion intruding into specimens could be reacted and generated into expansive substances, which can fill and refine the micro pores. Second, the formed erosion products could enhance the compactness of system and reduce the amount of $\mathrm{CH}$ in cement specimen $[21,49,50]$, so the microstructure and the performance of the specimens are improved. The higher the concentration of sulfate solution, the greater the concentration gradient between the solution and specimen surface. Therefore, more sulfate ion intrudes into specimen, and plenty of expansive substances are generated. If the expansive substances generated by sulfate attack can be accommodated by pores in system, the sulfate attack has a positive effect on performance of the specimens. Conversely, the sulfate attack destroys the thermodynamic equilibrium state of the system and results in micro damage, so it has a negative effect. Macroscopically, it is manifested as the decrease of the mechanical properties of the specimens. Although the compressive strength of paste and mortar attacked by sulfate for 4 months decreases with the increase of sulfate solution concentration, the corresponding compressive strength of the concrete first increases and then decreases. The maximum decreasing amount of the compressive strength of the specimens can reach up to $30 \%$. The flexural strength of the paste first increases and then decreases with increase of the sulfate solution concentration. However, the corresponding flexural strength of the mortar decreases, and the maximum decreasing amount can reach up to $50 \%$. The paste has a better resistance to sulfate attack, which is due to generation of plenty of 


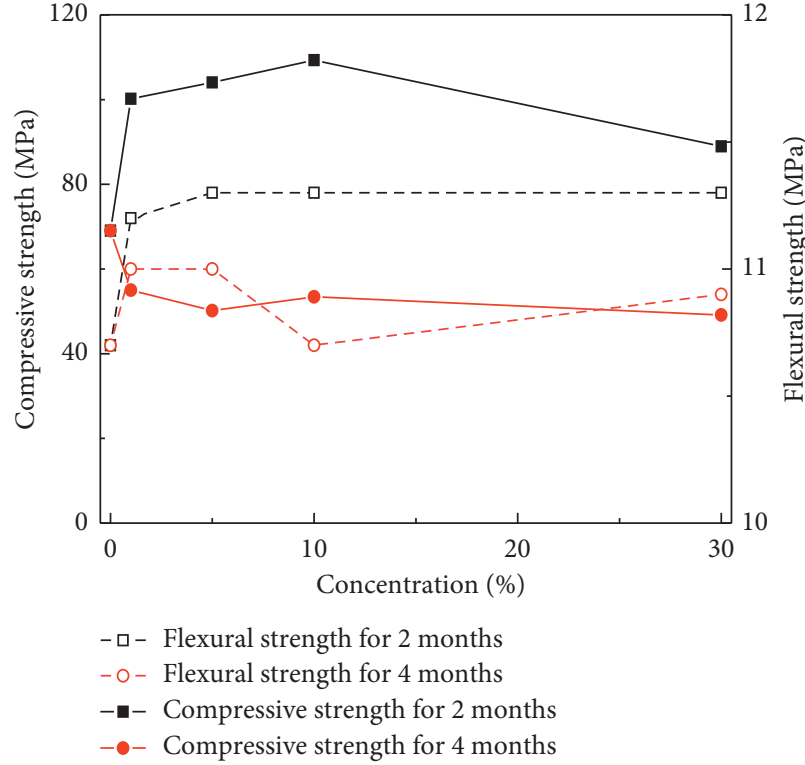

(a)

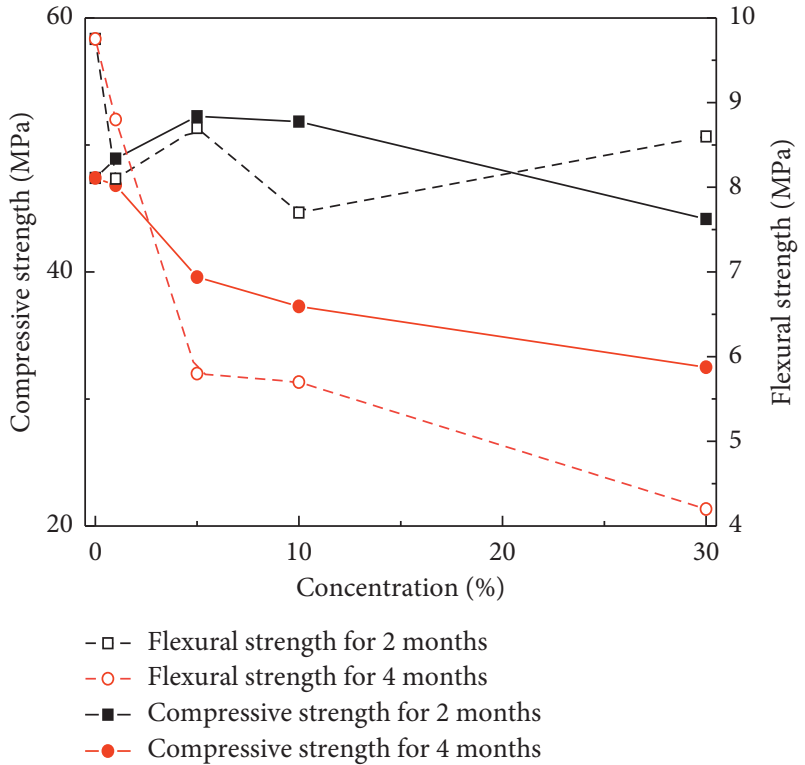

(b)

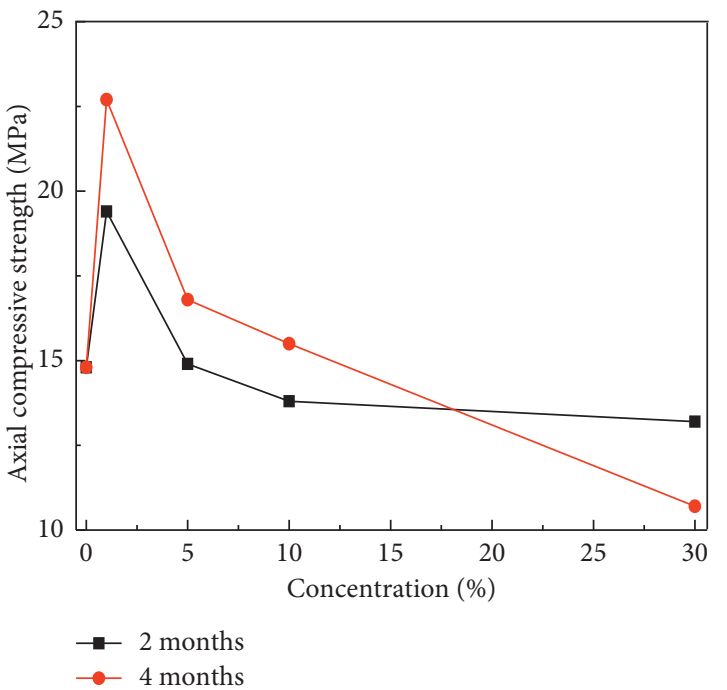

(c)

Figure 8: Mechanical properties of different specimens attacked by sulfate solution. (a) Paste. (b) Mortar. (c) Concrete.

hydration products resulting from the more usage of cementitious minerals per unit volume. The longer the erosion age, the more the sulfate ion intruding into specimens. More expansive substances are formed and reacted with $\mathrm{CH}$, which results in the micro damage and decrease of $\mathrm{pH}$ value of the system. With increasing erosion time, more and more hydration products are decomposed. Therefore, the sulfate attack has a negative effect on performance of the specimens. Macroscopically, it is manifested as the decrease of strength of various specimens.

\section{Conclusions}

(1) The relationship between the temperature and the Gibbs free energy of the erosion products generated during the sulfate attack was deduced. Theoretical orientation of sulfate attack on concrete was determined, and the critical sulfate ion concentration and forming conditions of erosion products were determined. The results show that the generation of the erosion products in cement concrete is related to temperature, relative humidity, and sulfate ion concentration, which affect each other. The dihydrate gypsum is preferentially generated when the temperature is less than $42^{\circ} \mathrm{C}$ and $\left[\mathrm{SO}_{4}^{2-}\right]$ concentration is more than $2.3 \times 10^{-3} \mathrm{~mol} / \mathrm{L}$. However, the corresponding formation $\left[\mathrm{SO}_{4}^{2-}\right]$ concentration and temperature of anhydrite are more than $4.2 \times 10^{-3} \mathrm{~mol} / \mathrm{L}$ and $42^{\circ} \mathrm{C}$, respectively. The theoretical thermodynamic stable temperature of $\mathrm{AFt}$ is about $97^{\circ} \mathrm{C}$, and the critical $\left[\mathrm{SO}_{4}^{2-}\right]$ concentration of AFt dominated significantly by temperature is no less 
than $2.8 \times 10^{-3} \mathrm{~mol} / \mathrm{L}$. The mirabilite and thenardite may be generated when the concentration of sulfate ion is more than $1.5 \times 10^{-3} \mathrm{~mol} / \mathrm{L}$. The mirabilite can be spontaneously crystallized when the temperature is less than $32.4^{\circ} \mathrm{C}$. Moreover, the theoretical thermodynamic stable temperature for thaumasite is less than $44^{\circ} \mathrm{C}$, and the corresponding critical $\left[\mathrm{SO}_{4}^{2-}\right]$ concentration is more than $0.0023 \mathrm{~mol} / \mathrm{L}$. Therefore, there is a significant difference in the theoretical temperature from that reported by existing documents.

(2) The phase composition, microstructure, crystal form, and morphology of erosion products of cement before and after sulfate attack were investigated by ESEM-EDS and XRD. The mechanism of sulfate attack on cement and concrete was investigated based on principles of chemical thermodynamics. The major erosion product of cement attacked by low concentration sulfate solution is rod-like AFt with a larger diameter-length ratio generated in the system, but plate-like dihydrate gypsum and granular sulfate salt are the major products when the concentration of sulfate solution is more than $10 \%$. Moreover, there exist the residual skeletons of C-S-H or $\mathrm{CH}$. The XRD spectra show that the phase composition, intensity, and width of diffraction peaks of erosion products in cement are changed before and after sulfate attack. The diffraction peaks' intensity of the AFt and dehydrate gypsum increases, but the corresponding diffraction peaks' intensity of the $\mathrm{CH}, \mathrm{C}-\mathrm{S}-\mathrm{H}$, and $\mathrm{C}-\mathrm{A}-\mathrm{H}$ decreases and even disappears. The sulfate solution concentration and erosion age have significant effects on the mechanical properties of the specimens. Although the compressive strength of the paste and mortar attacked by sulfate for 4 months decreases with the increase of sulfate solution concentration, the corresponding compressive strength of the concrete first increases and then decreases. This is due to the double effects, i.e., positive and negative effects, of the sulfate attack on performance of the specimens.

\section{Data Availability}

The data used to support the findings of this study are available from the corresponding author upon request.

\section{Conflicts of Interest}

The authors declare that they have no conflicts of interest.

\section{Acknowledgments}

This study was funded by the National Natural Science Foundation of China (grant nos. 51778632, U1434204, U1934217, and 51408614) and China Postdoctoral Science Foundation (grant nos. 2016M600675 and 2017T100647). Author has received research grants from the Guangdong Provincial Key Laboratory of Durability for Marine Civil
Engineering (grant nos. GDDCE14-03, 15-08, 17-2, and 18-16), Basic Research on Science and Technology Program of Shenzhen (JCYJ20170818143541342 and JCYJ20180305123935198), and Natural Science Foundation of Hunan Province of China (2017JJ3385).

\section{References}

[1] A. Neville, "The confused world of sulfate attack on concrete," Cement and Concrete Research, vol. 34, no. 8, pp. 1275-1296, 2004.

[2] M. Yao and J. Li, "Effect of the degradation of concrete friction piles exposed to external sulfate attack on the pile bearing capacity," Ocean Engineering, vol. 173, pp. 599-607, 2019.

[3] S. F. Etris, Y. R. Fiorni, and K. C. Lieb, "A new test for sulfate resistance of cements," Journal of Testing and Evaluation, vol. 2, no. 6, pp. 510-515, 1974.

[4] R. Dhole, M. D. A. Thomas, K. J. Folliard, and T. Drimalas, "Chemical and physical sulfate attack on fly ash concrete mixtures,” ACI Materials Journal, vol. 116, no. 4, pp. 31-42, 2019.

[5] M. Santhanam, M. D. Cohen, and J. Olek, "Mechanism of sulfate attack: a fresh look: part 2. proposed mechanisms," Cement and Concrete Research, vol. 32, no. 6, pp. 915-921, 2003.

[6] O. S. B. Al-Amoudi, "Attack on plain and blended cements exposed to aggressive sulfate environments," Cement and Concrete Composites, vol. 24, no. 3, pp. 305-316, 2002.

[7] L. Pel, H. Huinink, K. Kopinga, R. P. J. van Hees, and O. C. G. Adan, "Efflorescence pathway diagram: understanding salt weathering," Construction and Building Materials, vol. 18, no. 5, pp. 309-313, 2004.

[8] E. Álvarez-Ayuso and H. W. Nugteren, "Synthesis of ettringite: a way to deal with the acid wastewaters of aluminium anodising industry," Water Research, vol. 39, no. 1, pp. 65-72, 2005.

[9] L. Jiang, D. Niu, L. Yuan, and Q. Fei, "Durability of concrete under sulfate attack exposed to freeze-thaw cycles," Cold Regions Science and Technology, vol. 112, pp. 112-117, 2015.

[10] S. Valencia, G. William, A. D. Eugenia, and G. R. Mejia de, "Fly ash slag geopolymer concrete: resistance to sodium and magnesium sulfate attack," Journal of Materials in Civil Engineering, vol. 28, no. 12, Article ID 04016148, 2016.

[11] N. C. Axel, R. J. Torben, and C. Jonathan, "Formation of ettringite, $\mathrm{Ca}_{6} \mathrm{Al}_{2}\left(\mathrm{SO}_{4}\right)_{3}(\mathrm{OH})_{12} \cdot 26 \mathrm{H}_{2} \mathrm{O}$, AFt and monosulfate, $\mathrm{Ca}_{4} \mathrm{Al}_{2} \mathrm{O}_{6}\left(\mathrm{SO}_{4}\right) \cdot 14 \mathrm{H}_{2} \mathrm{O}, \mathrm{AFm}-14$, in hydrothermal hydration of Portland cement and of calcium aluminum oxide-calcium sulfate dihydrate mixtures studied by in situ synchrotron X-ray powder diffraction," Journal of Solid State Chemistry, vol. 177, pp. 1944-1951, 2004.

[12] C. D. Lawrence, "Mortar expansions due to delayed ettringite formation. Effects of curing period and temperature," Cement and Concrete Research, vol. 25, no. 4, pp. 903-914, 1995.

[13] R. H. Michael, K. B. Steven, and B. Ronald, "The evolution of structural changes in ettringite during thermal decomposition," Journal of Solid State Chemistry, vol. 179, no. 4, pp. 1259-1272, 2006.

[14] E. E. Hekal, E. Kishar, and H. Mostafa, "Magnesium sulfate attack on hardened blended cement pastes under different circumstances," Cement and Concrete Research, vol. 32, no. 9, pp. 1421-1427, 2002.

[15] H. A. F. Dehwah, "Effect of sulfate concentration and associated cation type on concrete deterioration and 
morphological changes in cement hydrates," Construction and Building Materials, vol. 21, no. 1, pp. 29-39, 2007.

[16] P. W. Brown, "Thaumasite formation and other forms of sulfate attack," Cement and Concrete Composites, vol. 24, no. 3-4, pp. 301-303, 2002.

[17] T. Liu, S. Qin, D. Zou, and W. Song, "Experimental investigation on the durability performances of concrete using cathode ray tube glass as fine aggregate under chloride ion penetration or sulfate attack," Construction and Building Materials, vol. 163, pp. 634-642, 2018.

[18] I. Biczok, Concrete Corrosion and Concrete Protection, Chemical Publishing, Palm Springs, CA, USA, 1967.

[19] F. Bellmann, B. Möser, and J. Stark, "Influence of sulfate solution concentration on the formation of gypsum in sulfate resistance test specimen," Cement and Concrete Research, vol. 36, no. 2, pp. 358-363, 2006.

[20] Z. Zhang, X. Jin, and W. Luo, "Long-term behaviors of concrete under low-concentration sulfate attack subjected to natural variation of environmental climate conditions," $\mathrm{Ce}$ ment and Concrete Research, vol. 116, pp. 217-230, 2019.

[21] X. Yu, Y. Zhu, Y. Liao, and D. Chen, "Study of the evolution of properties of mortar under sulfate attack at different concentrations," Advances in Cement Research, vol. 28, no. 10, pp. 617-629, 2016.

[22] M. Santhanam, "Effect of solution concentration on the attack of concrete by combined sulphate and chloride solutions," European Journal of Environmental and Civil Engineering, vol. 15, no. 7, pp. 1003-1015, 2011.

[23] P. B. Xie, "Mechanism of sulfate expansion II: vali DTA ion of thermodynamie theory," Cement and Concrete Research, vol. 22, no. 5, pp. 845-854, 1992.

[24] M. T. Blanco-Varela, J. Aguilera, and S. Martínez-Ramírez, "Effect of cement C3A content, temperature and storage medium on thaumasite formation in carbonated mortars," Cement and Concrete Research, vol. 36, no. 4, pp. 707-715, 2006.

[25] S. A. Hartshorn, J. H. Sharp, and R. N. Swamy, "The thaumasite form of sulfate attack in Portland-limestone cement mortars stored in magnesium sulfate solution," Cement and Concrete Composites, vol. 24, no. 3-4, pp. 351-359, 2002.

[26] P. Brown, R. D. Hooton, and B. Clark, "Microstructural changes in concretes with sulfate exposure," Cement and Concrete Composites, vol. 26, no. 8, pp. 993-999, 2004.

[27] X. C. Fu, W. X. Shenm, T. Y. Yao, and W. H. Hou, Physical Chemistry, Higher Education Press, Beijing, China, 2009.

[28] D. L. Ye, Shi Yong Wu Ji Wu Re Li Xu Shu Ju Shou Ce, Metallurgical Industry Press, Beijing, China, 2002.

[29] D. Freyer, S. Fischer, K. Kohnke, and W. Voigt, "Formation of double salt hydrates I. Hydration of quenched $\mathrm{Na}_{2} \mathrm{SO}_{4} \mathrm{CaSO}_{4}$ phases," Solid State Ionics, vol. 96, no. 1-2, pp. 29-33, 1997.

[30] G. W. Scherer, "Crystallization in pores," Cement and Concrete Research, vol. 29, no. 8, pp. 1347-1358, 1999.

[31] G. W. Scherer, "Stress from crystallization of salt," Cement and Concrete Research, vol. 34, no. 9, pp. 1613-1624, 2004.

[32] S. Jan, M. Jacques, and O. Ivan, Sulfate Attack on Concrete, Spon press, London, UK, 2002.

[33] J. Skalny, J. Marchand, and I. Odler, Sulfate Attack on Concrete, Spon Press, London, UK, 2002.

[34] J. R. Clifton and J. M. Pommersheim, Sulfate Attack of Cementitious Materials: Volumetric Relations and Expansions (NISTIR 5390), NIST, Gaithersburg, MA, USA, 1994.

[35] Z. D. Niu, F. Q. Cheng, C. B. Li, and X. Chen, Shui Yan Ti Xi Xiang Tu Ji Qi Ying Yong, Tianjin University Press, Tianjin, China, 2002.
[36] Thermoddem, http://thermoddem.brgm.fr/2019.

[37] GB175-2007, Common Portland Cement, China Standards Press, Beijing, China, 2008, in Chinese.

[38] GB/T 1346-2011, Test Methods for Water Requirement of Normal Consistency, Setting Time and Soundness of the Portland Cement, China Standards Press, Beijing, China, 2012, in Chinese.

[39] GB/T 17671-1999, Method of Testing Cements-Determination of Strength, China Standards Press, Beijing, China, 1999, in Chinese.

[40] GB/T 50081-2002, Standard for Test Method of Mechanical Properties on Ordinary Concrete, China Architecture \& Building Press, Beijing, China, 2014, in Chinese.

[41] S. B. Wang, S. X. Ji, Y. J. Liu, and K. Y. Hu, "Effect of alkali on expansion of sulfoaluminate cement," Journal of the Chinese Ceramic Society, vol. 14, no. 3, pp. 31-38, 1986.

[42] Y. H. Li, S. Y. Gao, P. S. Song, and S. P. Xia, "Effect of Pitzer mixing parameters on the solubility prediction of the phae system $\mathrm{HCl}-\mathrm{NaCl}-\mathrm{H}_{2} \mathrm{O}$," Acta Physico-Chimica Sinica, vol. 17, no. 1, pp. 91-94, 2001.

[43] J. G. Xue, "On the expansion associated with etringite formation," Journal of the Chinese Ceramic Society, vol. 2, pp. 252-256, 1984.

[44] J. F. Robert, "Salt damage in porous materials: how high supersaturations are generated," Journal of Crystal Growth, vol. 242, no. 3, pp. 435-454, 2002.

[45] N. Tsui, R. J. Flatt, and G. W. Scherer, "Crystallization damage by sodium sulfate," Journal of Cultural Heritage, vol. 4, no. 2, pp. 109-115, 2003.

[46] CCES 01-2004, Guide to Durability Design and Construction of Concrete Structures, China Architecture \& Building Press, Beijing, China, 2005, in Chinese.

[47] GB 50212-1991, Specification for Construction and Acceptance of Anticorrosive Engineering of Buildings, China plan publishing house, Beijing, China, 2002, in Chinese.

[48] K. P. Mehta, P. K. Mehta, and P. J. M. Monteiro, Concrete Structure, Properties and Materials, Tongji Press, Shanghai, China, 1991.

[49] Y. Gu, R.-P. Martin, O. Omikrine Metalssi, T. Fen-Chong, and P. Dangla, "Pore size analyses of cement paste exposed to external sulfate attack and delayed ettringite formation," Cement and Concrete Research, vol. 123, p. 105766, 2019.

[50] I. Tai, H. P. C. Sergio, and S. Ignacio, "The role of porosity in external sulphate attack," Cement and Concrete Composites, vol. 97, pp. 1-12, 2019. 